NBER WORKING PAPER SERIES

\title{
FOUR DECADES OF CANADIAN EARNINGS INEQUALITY AND DYNAMICS ACROSS WORKERS AND FIRMS
}

\author{
Audra Bowlus \\ Émilien Gouin-Bonenfant \\ Huju Liu \\ Lance Lochner \\ Youngmin Park \\ Working Paper 28757 \\ http://www.nber.org/papers/w28757
NATIONAL BUREAU OF ECONOMIC RESEARCH
1050 Massachusetts Avenue
Cambridge, MA 02138
May 2021

\begin{abstract}
We thank Jim Davies for his help on Canadian policy. Mauricio Torres Ferro and Tom Trivieri provided excellent research assistance. We received financial support for accessing and vetting the data from the Productivity Partnership, funded by the Social Sciences and Humanities Research Council of Canada. Lochner and Bowlus thank the Social Sciences and Humanities Research Council for its generous support. The views expressed in this paper are those of the authors and do not necessarily represent those of the Bank of Canada or Statistics Canada. The views expressed herein are those of the authors and do not necessarily reflect the views of the National Bureau of Economic Research.
\end{abstract}

At least one co-author has disclosed additional relationships of potential relevance for this research. Further information is available online at http://www.nber.org/papers/w28757.ack

NBER working papers are circulated for discussion and comment purposes. They have not been peer-reviewed or been subject to the review by the NBER Board of Directors that accompanies official NBER publications.

(C) 2021 by Audra Bowlus, Émilien Gouin-Bonenfant, Huju Liu, Lance Lochner, and Youngmin Park. All rights reserved. Short sections of text, not to exceed two paragraphs, may be quoted without explicit permission provided that full credit, including $\odot$ notice, is given to the source. 
Four Decades of Canadian Earnings Inequality and Dynamics across Workers and Firms Audra Bowlus, Émilien Gouin-Bonenfant, Huju Liu, Lance Lochner, and Youngmin Park NBER Working Paper No. 28757

May 2021

JEL No. E24,J24,J31,J62,L25

\section{$\underline{\text { ABSTRACT }}$}

This paper studies the evolution of individual earnings inequality and dynamics in Canada from 1983 to 2016 using tax files and administrative records. Linking these individuals to their employers (and rich administrative records on firms) beginning in 2001, it also documents the relationship between the earnings dynamics of workers and the size and growth of their employers. It highlights three main patterns over this period: First, with a few exceptions (sharp increase in top $1 \%$ and declining gender gap), Canada has experienced relatively modest changes in overall earnings inequality, volatility, and mobility between 1983 and 2016. Second, there is considerable variability in earnings inequality and volatility over the business cycle. Third, the earnings dynamics of individuals are strongly related to the size and employment growth of their employers.

Audra Bowlus

University of Western Ontario

London, Ontario, Canada N6A 5C2

abowlus@uwo.ca

Émilien Gouin-Bonenfant

Columbia University

New York, New 10027

eg3041@columbia.edu

Huju Liu

Statistics Canada

Ottawa, Ontario K1A 0T6

Canada

huju.liu@canada.ca

\author{
Lance Lochner \\ Department of Economics \\ Faculty of Social Science \\ Western University \\ 1151 Richmond Street, North \\ London, ON N6A 5C2 \\ CANADA \\ and NBER \\ llochner@uwo.ca \\ Youngmin Park \\ Bank of Canada \\ 234 Wellington Street \\ Ottawa, Ontario \\ K1A 0G9 \\ Canada \\ plyoungmin@gmail.com
}

A data appendix is available at http://www.nber.org/data-appendix/w28757 


\section{Introduction}

The rising inequality observed in many developed countries over the past several decades has garnered considerable attention. Changes in earnings inequality may signal structural transformations in the technology of production (as highlighted in the voluminous literatures on skill-biased technological change or polarization), shifts in the nature of international trade, evolving labor market institutions, or the influence of new economic policies and their incentives for work. Because the persistence of earnings differences across individuals is critical for understanding the implications of inequality for individual welfare, the evolution of earnings volatility and mobility are also of great interest. In this paper, we study the evolution of earnings inequality, volatility, and mobility in Canada from 1983 to 2016. We also study the extent to which the earnings dynamics of workers depend on the size and growth of the firms at which they work.

Most studies of Canadian earnings inequality rely on Census data or survey data like the Survey of Consumer Finances (SCF), Labour Force Survey (LFS), or Survey of Labour and Income Dynamics (SLID). ${ }^{1}$ These studies generally find modest long-term changes in inequality relative to the substantial increases observed in the U.S. (e.g., see the survey in Acemoglu and Autor, 2011). Morissette and Berube (1996) and Baker and Solon (2003) provide early studies of earnings mobility and dynamics in Canada using a $1 \%$ random sample of tax records from 1975 to 1993. Both studies document considerable persistence in earnings over the lifecycle, with Baker and Solon (2003) further showing that the variance of both transitory and persistent components increased over their sample period. Studying Canadian income mobility over more recent decades (using both survey and administrative data), several studies have documented increasing mobility with the duration between periods, although these studies continue to find considerable persistence in the tails of the earnings distribution (Beach and Finnie, 1998, 2004; Bowlus and Robin, 2012; Lammam, Karabegović, and Veldhuis, 2012). We are unaware of any Canadian studies focusing on the relationship between the earnings dynamics of workers and the employment or productivity dynamics of their firms; however, Gee, Liu, and Rosell (2020) highlight the important role of firms in explaining cross-sectional earnings inequality in Canada. We discuss these studies, as well as several others, further below.

Like other articles in this issue, we exploit several administrative and tax files. These records allow us to observe annual earnings for all Canadians who file income taxes in every year that they file from 1983 to 2016. Beginning in 2001, we are also able to link these individuals to their employers (and corresponding firm records), facilitating our analysis of joint worker and firm dynamics.

Our analysis provides a vast array of evidence on the evolution of earnings inequality and dynamics in Canada over the last four decades, all using the same data source, sampling scheme, and measures of earnings (with the sampling and measurement designed to facilitate comparisons with the studies focused on other countries in this issue). We let the data speak for themselves as much as possible. Here, we briefly

${ }^{1}$ For example, see Beaudry and Green (2000); Picot (2001); Boudarbat, Lemieux, and Riddell (2010); Brzozowski et al. (2010); Fortin et al. (2012); Beach (2016); Fortin and Lemieux (2015); and Green and Sand (2015). See Frenette, Green, and Picot (2006) for a discussion of the strengths and weaknesses of these data sources, and a comparison of family income inequality across them. 
highlight three broad sets of findings.

First, with a few notable exceptions, we find only modest changes in standard measures of overall earnings inequality, volatility, and mobility between 1983 and 2016. For example, the earnings for men at the 90th percentile relative to 10 th percentile increased by roughly $13 \%$, while this ratio declined by about $8 \%$ for women. This experience is quite different from the large increases in inequality documented in the U.S. (e.g., see the survey in Acemoglu and Autor, 2011). Canadian measures of annual or 5-year earnings volatility, as well as earnings mobility over more extended periods, also show little long-term trend. Based on these summary measures, one could be forgiven for thinking that nothing has changed in the Canadian labor market since the early 1980s, but this is not quite true. The earnings of women have risen substantially relative to men (by roughly 30\% at the median), and there has been a meteoric rise in earnings among those at the very top of the earnings distribution, as also documented by Saez and Veall (2005) and Veall (2012). More broadly, inequality increased somewhat over the top half of the earnings distribution, while it declined over the bottom half, resulting in modest changes overall. Although mobility patterns have remained remarkably stable over most of the earnings distribution, there was a shift toward less persistence in the middle of the distribution toward slightly more downward mobility from 1985 to 2005. Interestingly, this is coupled with sustained persistence at the top and bottom of the distribution.

Second, we find that despite relative stability of earnings inequality and volatility over the long-term, there is considerable variability over the business cycle. The major recession of the early 1990s and, to a lesser extent, the Great Recession of 2008-09 induced sharp (temporary) increases in earnings inequality and volatility, driven mainly by significant earnings losses by men at the bottom of the earnings distribution and younger workers. However, those at the very top of the earnings distribution (i.e., top 1\%) also experienced heavy losses during these downturns.

Third, we show that the earnings dynamics of workers are strongly related to the size and employment growth of their employers. Most interestingly, we find that workers at fast-growing firms experience faster earnings growth and less downside risk than workers at rapidly shrinking firms, who experience low (or negative) average earnings growth and little upside risk. Meanwhile, workers at firms with stable employment typically experience moderate earnings growth with little upside or downside risk. Our results further reveal that the positive relationship between workers' average earnings growth and their firms' employment growth is broad-based, evident for those with high and low recent earnings levels, those at large and small firms, and those at young and old firms.

The rest of this paper is organized as follows. Section 2 discusses our main source of data, sampling, and variable definitions, while Section 3 provides a very brief overview of the economic and policy environment in Canada over the period we study. Our empirical analysis is contained in Sections 4 and 5. The former contains our individual-level analysis of earnings inequality, volatility, and mobility, while the latter contains our analysis of the joint dynamics of worker earnings and firm employment. Section 6 concludes. 


\section{Data}

We use the Canadian Employer-Employee Dynamics Database (CEEDD) for the analysis in this paper. The CEEDD is a linkable environment developed by Statistics Canada that consists of several administrative and tax files, including individual tax files (T1 General - Income Tax and Benefit Return), individual employment remuneration files (T4 Statement of Remuneration Paid), individual records of employment (Record of Employment (ROE)), the Longitudinal Immigration Database (IMDB), corporation tax files (T2 Corporation Income Tax Return), and unincorporated business tax files (T1 Business Declarations). Altogether, it provides rich information on individual demographics, employment, job mobility, self-employment and entrepreneurship, and firm characteristics.

The individual part of the CEEDD, which goes back to the early 1980s, enables a long-term analysis of income inequality and dynamics. It contains information on demographics (year of birth, gender, marital status, province or territory of residence) and income (employment income, self-employment income, pension income, investment income, government transfers, etc.); however, information on educational attainment and occupation is unavailable.

The individual-level data are drawn from the T1 Personal Master File (T1PMF), which contains annual personal income tax records for all Canadian tax filers who filed their tax returns before a specified cut-off date. While the exact cut-off date varies over time, it is usually sometime in December one year after the tax reference year (Messacar, 2017). Only about 3.5-4.8\% of all tax filers do not file tax returns before this date. $^{2}$ These late filers are not included in T1PMF; however, they are included in the T1 Historical Personal Master File (T1HPMF), which is more comprehensive than T1PMF, but less timely.

We use the T1PMF (rather than T1HPMF), because it covers a more recent and longer time period. At the time this analysis was conducted, T1PMF covered the period 1983-2016, while T1HPMF only covered 1987-2014. Importantly, the exclusion of late filers does not appear to distort measures of the income distribution. While Messacar (2017) finds that late tax filers tend to be more prevalent among young individuals, non-residents, emigrants, very low earners, and those with final tax balances close to zero, this has little effect on estimated earnings distributions, including top-earnings percentiles. ${ }^{3}$ Over our sample period (1983-2016), the T1PMF includes records each year for 90-94\% of all 25- to 55-year-old Canadians (Appendix Figure A1).

A standard concern when studying inequality based on tax records is the potential for non-filing, especially among very low earners. Fortunately, as discussed by Frenette, Green, and Picot (2006), even zero-earners in Canada have had a strong incentive to file their taxes after the 1993 introduction of the refundable Child

\footnotetext{
2The cut-off date before which a tax return may be included in T1PMF differs from the date by which an individual must submit a return to the Canada Revenue Agency (CRA) or after which interest charges or penalties begin to accrue on outstanding tax balances owed. The latter date is typically April 30 in Canada.

${ }^{3}$ Regarding top-earnings percentiles, Messacar (2017) finds little difference when late filers are included or excluded from the analysis. For example, in 2010 , he finds differences of only $\$ 200$ and $\$ 2,550$ at the 99 th and 99.9 th percentiles of employment income, respectively. He also finds that the likelihood of delayed tax filing is only weakly correlated with changes in individual circumstances (e.g., changes in employment earnings or receiving unemployment benefits).
} 
Tax Benefit (and the earlier introduction of the Goods and Services Tax Credit in 1989-1990). Despite these increased incentives to file, Appendix Figure A1 shows that coverage rates for the T1PMF increased by only about $2 \%$ between the mid-1980s and mid-1990s (peaking at roughly $94 \%$ ). ${ }^{4}$ The modest year-to-year changes in observed filing behavior are unlikely to have any notable impacts on the evolution of broad measures of inequality during our sample period. Indeed, we observe no unusual changes at the low end of the earnings distribution between 1992 and 1993, when (and where) filing incentives increased the most. ${ }^{5}$

\subsection{Sample selection and earnings measures}

Our analysis focuses on annual individual earnings as measured by the sum of employment income (wages, salaries, and commissions) reported on T4 slips from all jobs and other taxable receipts from employment (e.g., tips, gratuities, or director's fees) that are not reported on T4 slips. Self-employment income is not considered. All earnings from 1983 to 2016 are denominated in 2018 Canadian dollars using the Canadian Consumer Price Index. Denote these earnings for individual $i$ in year $t$ by $\tilde{y}_{i, t}$.

To ensure cross-country comparability and to reduce the impact of school-to-work transitions and retirement on earnings dynamics, our analysis only uses earnings observations for individuals when they are ages 25-55. Even within these ages, not everyone appears in the data every year. Individuals may file late, or they may not file taxes at all during a year in which they have little or no income. Some individuals may be out of the country. Due to high rates of immigration to and emigration out of Canada, we omit (or leave as missing) any earnings measures that are missing before the first year someone is observed filing their taxes or any earnings measures after the last year they are observed filing; otherwise, we treat any missing earnings observations (i.e., in-between years with non-missing earnings) as zeros (i.e., set $\tilde{y}_{i, t}=0$ ). ${ }^{6}$ The latter implicitly assumes that missing observations in the middle of someone's time series of tax filings reflect years with no earnings. Although this could be problematic for individuals who simply filed later than the T1PMF cut-off date, we ultimately trim these and other very low earnings measures in nearly all of our analysis to minimize the influence of temporary employment and weak labor market attachment. ${ }^{7}$

We define a minimum earnings threshold in year $t, \underline{y}_{t}$, as the amount a worker could earn by working part time (20 hours per week) for a quarter of the year (13 weeks) at the real minimum wage for that year. Because Canada does not have a federal minimum wage, the imposed minimum wage is assumed to be the

\footnotetext{
${ }^{4}$ Based on the T1 Family File, which combines records from the T1PMF and other tax forms, Frenette, Green, and Picot (2006) report a 1\% increase in tax file coverage rates (from 95\% to 96\%) between 1992 and 1993.

${ }^{5}$ To the extent that any marginal-filing low earners (from high-filing years) earn less than the minimum earnings trimming threshold imposed below, they would have no effect on our analysis of annual earnings. To the extent that some of these marginal filers earn between our minimum threshold and the 10th percentile, any increase in their filing rate would lower the 10th percentile values. Our figures show no evidence of unusual changes in these low earnings percentiles between 1992 and 1993.

${ }^{6}$ This approach implicitly assumes that individuals are out of the country prior to their first observed filing year or after their last observed filing year.

${ }^{7}$ Recall that, by itself, the exclusion of late filers has little effect on earnings distributions (Messacar, 2017). As discussed next, our analysis of annual earnings measures trims very low earnings observations, so setting missing observations to zero has no effect on most of our results. Treatment of missing observations only affects our calculation of "permanent" earnings measures, which are primarily used in our analysis of earnings mobility. As discussed in Section 4.3, alternative treatments of missing observations yield nearly identical mobility patterns for permanent earnings.
} 
lowest among all provincial minimum wages at the time. ${ }^{8}$ The measure of annual earnings we use in our empirical analysis, $y_{i, t}$, equals $\tilde{y}_{i, t}$ if $\tilde{y}_{i, t}>\underline{y}_{t}$; otherwise, it is set to missing. In much of our analysis, we focus on the natural logarithm of this annual earnings measure, $\log \left(y_{i, t}\right)$. We also calculate residualized $\log$ earnings $\varepsilon_{i, t}$ from regressions of $\log \left(y_{i, t}\right)$ on annual age dummies separately by gender and year, thereby removing average lifecycle effects on earnings. (Note that these residuals are also missing whenever earnings are below the threshold.)

Some of our analysis focuses on (residual) log earnings growth based on $\varepsilon_{i, t}$. To that end, we construct annual and 5-year earnings growth: $\Delta^{1} \varepsilon_{i, t} \equiv \varepsilon_{i, t+1}-\varepsilon_{i, t}$ and $\Delta^{5} \varepsilon_{i, t} \equiv \varepsilon_{i, t+2}-\varepsilon_{i, t-3}$, where the latter is roughly centered on year $t .^{9}$

Finally, we calculate two measures of "permanent" earnings to minimize the effects of year-to-year fluctuations. Our main measure of permanent earnings is designed to focus on the distribution and dynamics of earnings for individuals with moderate to strong labor market attachment, while we also consider an alternative measure that facilitates an analysis of long-term earnings mobility that incorporates workers who may be less attached, including those with very low or zero earnings for multiple years. In both cases, we begin by calculating $P_{i, t}$ as the average of non-missing earnings over three years $\left(\tilde{y}_{i, t}, \tilde{y}_{i, t-1}\right.$, and $\left.\tilde{y}_{i, t-2}\right)$. Our main measure reflects this average whenever (i) $\tilde{y}_{i, t}$ is non-missing (i.e., all years from first to last observed filing) and (ii) at least two of the earnings measures are above the earnings threshold for their respective years; otherwise, this measure is set to missing. The second restriction ensures that this measure is always positive. Most of our analysis uses residualized permanent earnings, $\varepsilon_{i, t}^{P}$, after removing lifecycle effects via regressions of $\log \left(P_{i, t}\right)$ on annual age dummies separately by gender and year. Our analysis of long-term earnings mobility considers an alternative permanent earnings measure that also begins with $P_{i, t}$, but this measure requires only one of the three earnings measures to be above the minimum earnings threshold. Further, it is not adjusted for age, gender, or year effects. We let $\tilde{P}_{i, t}$ denote this alternative permanent earnings measure.

Table 1 provides an overview of our data every five years. Panel A reports the number of observations, mean and standard deviation of annual earnings for the full sample, share of women, average earnings by gender, and the age distribution. Panel B reports selected percentiles of the annual earnings distribution for men and women combined. For cross-country comparison, earnings in this table only are converted to U.S. dollars using the 2018 exchange rate (after first deflating all values to 2018 dollars). The number of workers in our sample increases from 8 million to 10.8 million over the 30 -year period. The share of female workers has also increased over time as women have entered the labor market at higher rates. We also see a sizeable

\footnotetext{
${ }^{8}$ Appendix Figure A2 shows minimum wages for each Canadian province over time, with the lowest provincial minimum wage denoted by the solid black line with diamond markers.

${ }^{9}$ When calculating these earnings growth measures, we require that earnings in the earlier period exceeds the earnings threshold for that year, while we only require that earnings in the later year exceeds one-third of that year's threshold. More precisely, the later residuals, say $\varepsilon_{i, t+1}$, are estimated using the sample for which earnings exceed one-third the threshold for that year (i.e., $\left.\tilde{y}_{i, t+1}>\underline{y}_{t+1} / 3\right)$. Thus, we actually calculate two sets of residuals for every year based on the two different restrictions on minimum earnings.
} 
increase in average earnings for women relative to men over time, as well as a gradual aging of the population associated with the Baby Boom. While earnings have increased throughout the distribution, the magnitudes of the increases clearly differ across the distribution, as we explore in detail below.

Table 1: Descriptive statistics for selected cross-sectional samples

\begin{tabular}{|c|c|c|c|c|c|c|c|c|c|c|}
\hline \multicolumn{11}{|c|}{ A. Basic summary statistics } \\
\hline \multirow[b]{2}{*}{ Year } & \multirow[b]{2}{*}{$\begin{array}{l}\text { Obs. } \\
\text { (mill.) }\end{array}$} & \multirow[b]{2}{*}{$\begin{array}{c}\text { Mean } \\
\text { earnings }\end{array}$} & \multirow{2}{*}{\multicolumn{2}{|c|}{$\begin{array}{l}\text { Std. dev. } \\
\text { earnings }\end{array}$}} & \multirow[b]{2}{*}{$\begin{array}{c}\text { Women } \\
\text { share }(\%)\end{array}$} & \multicolumn{2}{|c|}{ Mean earnings } & \multicolumn{3}{|c|}{ Age shares $(\%)$} \\
\hline & & & & & & Men & Women & {$[25,35]$} & {$[36,45]$} & {$[46,55]$} \\
\hline 1985 & 8.0 & 35,968 & 33 , & 399 & 44.1 & 44,353 & 25,351 & 47.1 & 32.2 & 20.7 \\
\hline 1990 & 9.3 & 36,590 & 39 , & 164 & 46.7 & 44,886 & 27,107 & 43.9 & 34.5 & 21.6 \\
\hline 1995 & 9.6 & 36,770 & 42 , & 218 & 47.3 & 44,351 & 28,309 & 37.9 & 36.1 & 25.9 \\
\hline 2000 & 10.2 & 40,736 & 74 & 135 & 48.4 & 49,652 & 31,220 & 33.2 & 36.9 & 29.9 \\
\hline 2005 & 10.5 & 41,855 & 75 , & 630 & 49.0 & 50,766 & 32,582 & 32.7 & 34.0 & 33.3 \\
\hline 2010 & 10.6 & 43,719 & 62 & 509 & 49.2 & 51,841 & 35,331 & 34.0 & 30.8 & 35.3 \\
\hline 2015 & 10.8 & 45,759 & 67 , & 350 & 48.8 & 53,961 & 37,151 & 36.0 & 31.1 & 33.0 \\
\hline \multicolumn{11}{|c|}{ B. Selected percentiles of annual earnings distribution (men and women combined) } \\
\hline Year & $P 1$ & P5 & $P 10$ & $P 25$ & $P 50$ & P75 & $P 90$ & P95 & $P 99$ & $P 99.9$ \\
\hline 1985 & 2,131 & 4,458 & 7,460 & 16,627 & 32,075 & 49,425 & 65,964 & 77,268 & 113,502 & 268,906 \\
\hline 1990 & 2,075 & 4,626 & 7,798 & 17,003 & 32,221 & 49,259 & 66,940 & 79,466 & 121,651 & 315,828 \\
\hline 1995 & 2,131 & 4,458 & 7,460 & 16,627 & 32,075 & 49,425 & 65,964 & 77,268 & 113,502 & 268,906 \\
\hline 2000 & 2,200 & 5,045 & 8,483 & 18,199 & 33,515 & 52,113 & 72,590 & 88,891 & 159,125 & 593,560 \\
\hline 2005 & 2,236 & 5,054 & 8,537 & 18,387 & 33,918 & 53,292 & 75,842 & 93,849 & 169,383 & 623,492 \\
\hline 2010 & 2,566 & 5,492 & 9,169 & 19,406 & 35,422 & 56,354 & 80,244 & 100,141 & 176,748 & 552,109 \\
\hline 2015 & 2,872 & 6,147 & 10,027 & 20,628 & 36,788 & 58,875 & 83,446 & 104,879 & 186,188 & 570,090 \\
\hline
\end{tabular}

Notes: Annual earnings reported in 2018 U.S. dollars.

\section{Economic and Policy Environment in Canada: 1983-2016}

Before getting into our empirical analysis, we provide a very brief overview of the Canadian economy over the past four decades, emphasizing factors that have been shown to or are likely to have impacted the evolution of earnings inequality and dynamics.

Figure 1 documents real GDP per capita and employment rates for men and women ages 25-54 over time. Since the early 1980s, male employment rates have hovered around $85 \%$, while female employment rates increased from less than $60 \%$ to about $78 \%$ at the onset of the Great Recession, stabilizing thereafter. Two major recessions stand out — that of the early 1990s and the global Great Recession of 2008-09. The early 1990s recession was much deeper and more protracted in Canada than in the U.S., with many Canadian firms restructuring, downsizing, and ultimately failing over this period. Fortin (1996) argues that tight monetary and fiscal policy explain the stronger severity in Canada: the Bank of Canada maintained high interest rates (relative to the U.S.) to reduce inflation, and the rising fiscal deficits (partially due to high interest rates 
and the recession itself) led to fiscal austerity, including large cuts to public sector employment. Freedman and Macklem (1998) argue that the recession was exacerbated by other concurrent secular changes, such as increasing competition from international trade. Figure 1 shows that, during the early 1990s recession, both output and employment (especially among men) dropped considerably between 1989 and 1992. While output and the female employment rate recovered over a few years, the male employment rate never returned to its pre-recession peak. By comparison, the Great Recession produced much sharper but smaller drops in output and employment in Canada. Output recovered quickly, while employment was slower to recover (and never fully did for men).

The shaded vertical bars in Figure 1 (and subsequent figures) indicate years with at least one quarter of negative GDP per capita growth. The downturns in 1986, 2001, and 2003 were all only a single quarter in duration and were not formally labeled recessions. The most recent downturn reflects a 6-quarter period of economic stagnation with modest negative growth in the first two quarters of 2015 and then again in the second quarter of 2016.

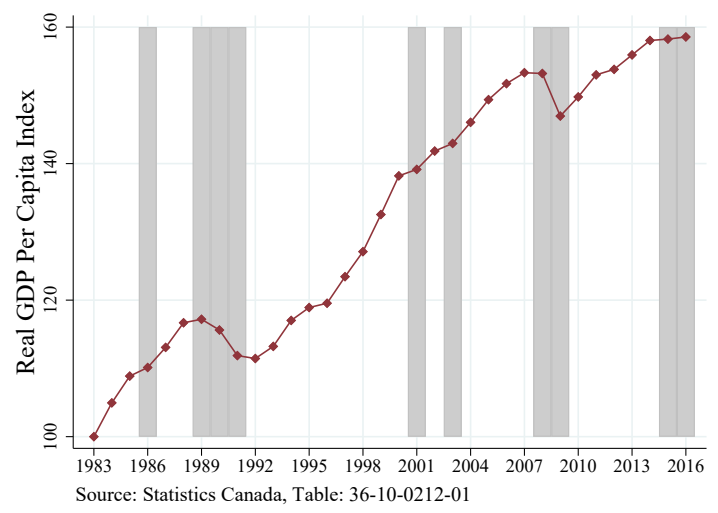

(a) Real GDP per capita

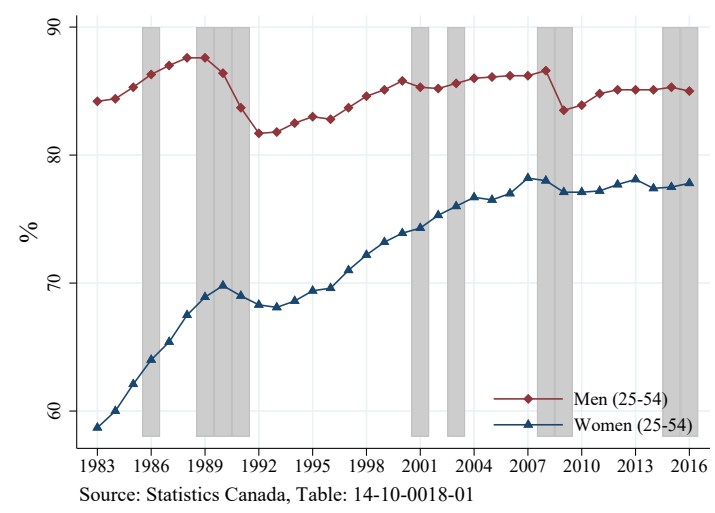

(b) Employment rate for men and women ages 25-54

Figure 1: Canadian macroeconomic conditions, 1983-2016

As Canada has a small open economy, trade can have important effects on the economy and the distribution of wages and earnings. After the 1988 Free Trade Agreement (FTA) with the U.S., and its later extension to the 1994 North American Free Trade Agreement (NAFTA), the Canadian economy relied more heavily on international trade - the shares of exports and imports in GDP both increased from 25\% in 1989 to $44 \%$ and 39\%, respectively, in 2000. According to Trefler (2004), the Canada-U.S. FTA caused a substantial reallocation of workers and other resources across plants and industries, leading to a $5 \%$ reduction in jobs and 6\% increase in labor productivity in manufacturing between 1988 and 1996. Such a major reallocation is likely to have destroyed some workers' job-specific skills and altered the match quality of workers and firms, both of which may have had lasting impacts on the distribution of earnings.

More recently, the oil and gas boom from roughly 2000 to 2015 clearly benefited the economies of Alberta, Saskatchewan, and Newfoundland, with all experiencing substantial wage growth (relative to the 
rest of Canada) over this period. While Fortin and Lemieux (2015) show that this boom generated broad benefits for workers in the affected provinces, reducing inequality in some cases, its impact on overall inequality in Canada is likely to have been modest.

Immigration is also an important factor for Canada, with slightly more than one-in-five of all Canadians having immigrated to the country. In 1976, Canada set its immigration priorities in the Immigration Act which, among other things, led to the formation of the Economic Class of immigrants (i.e., immigrants who are admitted based on their education and skills, with the intent of matching labor market needs). In the 1980s, the Economic Class was expanded to encourage business people and entrepreneurs to bring their skills and financial assets to Canada to set up businesses and create employment opportunities. As of 2018, the Economic Class accounted for more than half of all immigration to Canada. Aydemir and Borjas (2007) find that the large inflows of skilled immigrants weakened the growth in Canada's university premium.

Another potentially important trend has been the roughly 50\% increase in real minimum wages over the past few decades. This is likely to impact inequality at the bottom of the distribution through direct effects on hourly wages and indirect effects on employment and hours of work. Appendix Figure A2 shows minimum wages for each Canadian province over time, distinguishing those for the four most populous provinces. (The solid black line with diamond markers reflects the lowest provincial minimum wage each period.) Fortin et al. (2012) argue that increases in minimum wages in British Columbia, Ontario, and Quebec during the 1990s had modest impacts on the lower end of the wage distribution in those provinces. Fortin and Lemieux (2015) show that the sizeable increases in minimum wages (across all provinces) beginning in the mid-2000s can explain much of the increase in wages at the 10th percentile, accounting for observed declines in wage inequality over the bottom half of the distribution. The more widespread nature of the increases in the 2000s (compared to the 1990s increases) suggests that they are likely to have had more important impacts on national inequality measures; however, the compression effects on lower wage levels need not translate into compression in earnings at the bottom of the distribution.

The decline of unions may also influence the evolution of inequality. Between 1984 and 2015, the union coverage rate in Canada fell from $46 \%$ to $29 \%$ for men and from $37 \%$ to $32 \%$ for women (Card, Lemieux, and Riddell, 2020). While these changes (especially for men) are sizeable, Card, Lemieux, and Riddell (2004) suggest that stronger de-unionization in the U.S. and U.K. over the 1980s and 1990s may have contributed to even sharper increases in inequality in those countries. In recent years, Card, Lemieux, and Riddell (2020) estimate that unions reduce the variance of log wages among Canadian men by less than $10 \%$, with no effects on wage inequality among Canadian women.

Finally, government tax and transfer policies can affect earnings inequality, largely through incentive effects on labor supply. We briefly comment on some of the changes most likely to have impacted Canadian earnings distributions over our sample period. ${ }^{10}$ First, we note two major federal tax reforms that are most

\footnotetext{
${ }^{10}$ See Frenette, Green, and Milligan (2009) for an analysis of the effects of changes in Canadian tax and transfer policy on after-tax income inequality from 1980 to 2000.
} 
likely to have affected top earners (through labor supply incentives or reporting for tax purposes): the top tax rate was lowered from $34 \%$ to $29 \%$ in 1988 , while it was raised from $29 \%$ to $33 \%$ in 2016. Provincial tax rates also declined in the late 1990s, which tended to benefit high-income families relatively more. Several tax and transfer policy changes in the late 1990s created stronger work incentives for lower-income families, especially those with children. Major changes in Unemployment Insurance (now referred to as Employment Insurance in Canada) and social assistance directly encouraged work (Frenette, Green, and Milligan, 2009; Finnie and Irvine, 2011), while the introduction of the National Child Benefit Supplement (NCBS) and its integration with social assistance in many provinces helped to reduce the "welfare wall" generated by dollar-for-dollar drops in benefits with income (Milligan and Stabile, 2007; Milligan, 2016). Along with these changes, provincial expansions in job-protected maternity/parental leave during the early 1990s and in 2000 are also likely to have had greater effects on female (relative to male) labor supply and earnings (Baker and Milligan, 2008).

\section{Earnings Inequality, Dynamics, and Mobility in Canada: 1983-2016}

This section documents individual earnings inequality, dynamics, and mobility in Canada from 1983-2016 using the T1PMF tax file discussed in Section 2.

\subsection{Earnings inequality over time}

We begin by studying the evolution of earnings inequality, distinguishing between long-term trends and shortterm cyclical patterns (especially responses to the major recession of 1989-1991 and the Great Recession of 2008-09), followed by a brief accounting of earnings concentration at the top of the earnings distribution.

Long-term trends. In 1985, median earnings for Canadian men were about $\$ 55,000$ Canadian (denominated in 2018 dollars), nearly double the roughly $\$ 30,000$ earned by the median Canadian woman. Men at the 90th percentile earned nearly seven times as much as men at the 10th percentile, while women at the 90th percentile earned about nine times as much as women at the 10th percentile.

Table 2 reports several percentiles of the log earnings distributions for men and women in both 1985 and 2015, providing a summary of long-term changes in Canadian earnings inequality over a 30-year period. Figures 2 and 3 show changes in various percentiles over time (relative to their initial 1983 value), where the latter focuses on upper earnings percentiles, including the top $1 \%, 0.1 \%$, and $0.01 \%$. Together, these figures and Table 2 show that between 1985 and 2015, Canadian women experienced sizeable increases in earnings throughout the distribution — by about $30 \log$ points at the median and more everywhere else. ${ }^{11}$ Canadian men did not fare as well, with their sizeable earnings advantage relative to women narrowing considerably at all earnings percentiles (by half at the median). While men at the top and bottom of the earnings distribution

\footnotetext{
${ }^{11}$ As documented by Fortin et al. (2012) and Green and Sand (2015), these findings are consistent with time patterns for hourly and weekly wages based on Census and LFS data.
} 
experienced healthy gains, men at the 25th and 50th percentiles are no better off today than they were more than 30 years earlier. Among both men and women, those at the very top of the earnings distribution (i.e., top $1 \%$ and above) gained substantially. Between 1983 and 2007, earnings shot up more than 50 log points for men and women at the 99th percentile and more than doubled for those in the top $0.1 \%$. Following the Great Recession, earnings fell substantially for men in the top $0.1 \%$, while earnings were largely stagnant for their female counterparts.

Table 2: Percentiles of $\log \left(y_{i, t}\right)$ for Men and Women, 1985 and 2015

\begin{tabular}{lccccc}
\hline & \multicolumn{2}{c}{ Men } & & \multicolumn{2}{c}{ Women } \\
\cline { 2 - 3 } \cline { 5 - 6 } & 1985 & 2015 & & 1985 & 2015 \\
\hline$P 5$ & 9.03 & 9.18 & & 8.40 & 8.83 \\
$P 10$ & 9.56 & 9.68 & & 8.85 & 9.31 \\
$P 25$ & 10.37 & 10.39 & & 9.62 & 10.02 \\
$P 50$ & 10.91 & 10.94 & & 10.31 & 10.61 \\
$P 75$ & 11.23 & 11.38 & & 10.72 & 11.06 \\
$P 90$ & 11.47 & 11.73 & & 11.04 & 11.42 \\
$P 95$ & 11.63 & 11.97 & & 11.20 & 11.59 \\
$P 99$ & 12.06 & 12.59 & & 11.48 & 12.05 \\
$P 99.9$ & 13.03 & 13.82 & & 11.96 & 12.90 \\
$P 99.99$ & 14.24 & 15.14 & & 12.95 & 13.96 \\
$P 90-P 10$ & 1.92 & 2.05 & & 2.19 & 2.11 \\
$P 90-P 50$ & 0.57 & 0.79 & & 0.73 & 0.82 \\
$P 50-P 10$ & 1.35 & 1.27 & & 1.46 & 1.30 \\
\hline
\end{tabular}

Notes: Due to sample sizes and confidentiality rules, we are unable to report earnings at the 99.99 percentile for women prior to 1988 . We impute the 1985 value of $P 99.99$ for women using its 1988 value and 1985-1988 change for P99.9.

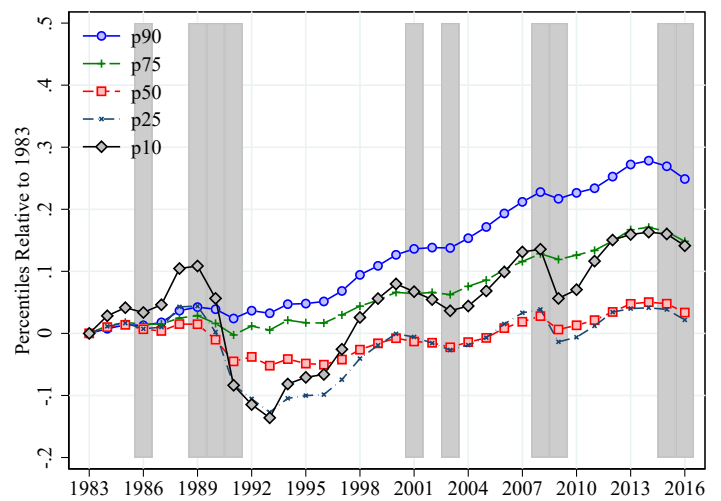

(a) Men

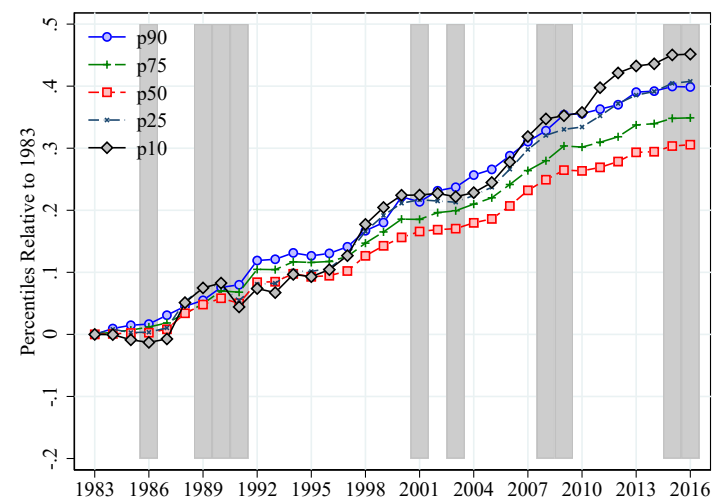

(b) Women

Figure 2: Changes in percentiles of $\log \left(y_{i, t}\right)(1983=0)$

These trends imply that over the past few decades, men experienced a modest increase in inequality 


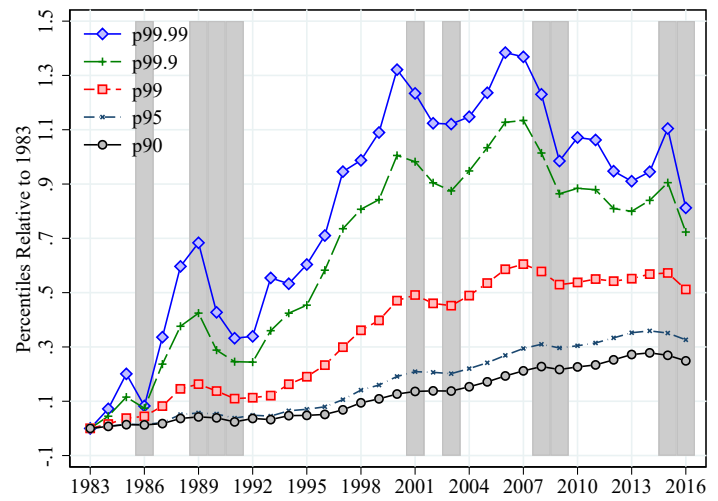

(a) Men

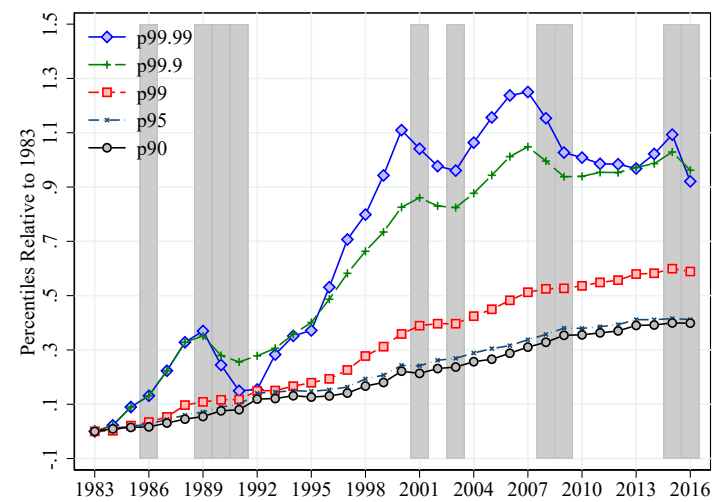

(b) Women

Figure 3: Change in upper percentiles of $\log \left(y_{i, t}\right)(1983=0)$

Notes: Due to sample sizes and confidentiality rules, we are unable to report earnings at the 99.99 percentile for women prior to 1988. In panel (b), we impute the 1983-1988 changes in P99.99 for women using their changes for P99.9.

(mostly coming during the early 1990s recession) as measured by the 90-10 percentile difference or standard deviation of log earnings (see Figure 4), while these measures of earnings inequality declined slightly for women. ${ }^{12}$ As discussed in Green and Sand (2015), the evolution of inequality in Canada differed at the top and bottom of the earnings distribution. Both men and women saw earnings inequality increase in the top half of the distribution, while inequality declined at the bottom. See Figure 5, which shows the evolution of 90-50 and 50-10 percentile differences in log earnings. ${ }^{13}$ The main driver of the long-run difference in earnings inequality between Canadian men and women was the stronger increase in inequality at the top for men, with their 90-50 difference rising $22 \log$ points between 1985 and 2015 compared to just $9 \log$ points for women. ${ }^{14}$ Among women, the decline in the 50-10 difference more than offset the modest increase in the 90-50 difference. These general patterns differ markedly from those documented by Guvenen et al. (2018) and Heathcote, Perri, and Violante (2010) for the U.S. over the same period, where overall earnings inequality rose substantially more due to a stronger secular increase in the $90-50$ difference and a sharp increase in the $50-10$ difference after $2000 .{ }^{15}$

These long-term trends in inequality (at both the top and bottom of the earnings distribution) are quite similar when looking at residualized annual $\left(\varepsilon_{i, t}\right)$ or permanent $\left(\varepsilon_{i, t}^{P}\right)$ earnings. (See Appendix Figures A3A8.) Thus, the evolution of inequality in Canada over our sample period does not appear to be driven

\footnotetext{
${ }^{12}$ Figure 4 reports $2.56 \times$ the standard deviation of earnings, which would equal the $90-10$ difference if earnings were normally distributed. The smaller 90-10 difference (for men) indicates that the earnings distribution has fat tails relative to a normal distribution.

${ }^{13}$ Based on data from the Canadian LFS, Fortin and Lemieux (2015) conclude that much of the increase in wages at the bottom relative to middle of the distribution since the mid-2000s (especially among women) can be explained by increases in minimum wages (see Figure A2); however, Figure 5 shows no obvious break in trend for the 50-10 difference in log earnings for men or women during this period.

${ }^{14}$ The sharper increase in the 90-50 difference for men relative to women is largely driven by differences in trends for median earnings, which were largely stagnant for men but increased over $30 \log$ points for women (see Figure 2).

${ }^{15}$ Acemoglu and Autor (2011) document qualitatively similar U.S. patterns for hourly wages.
} 


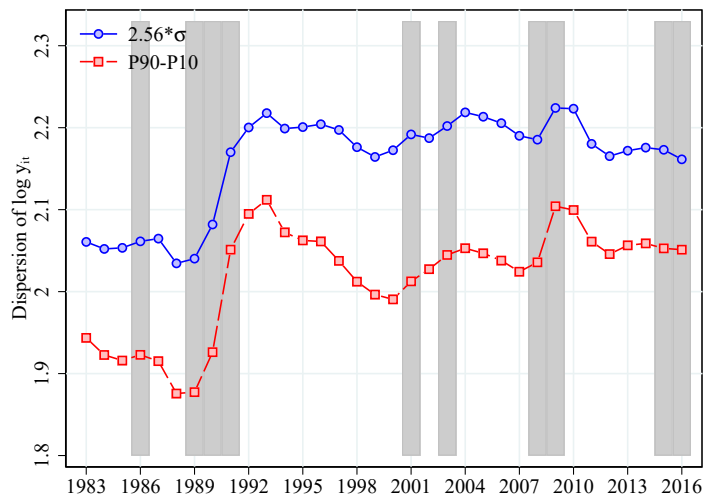

(a) Men

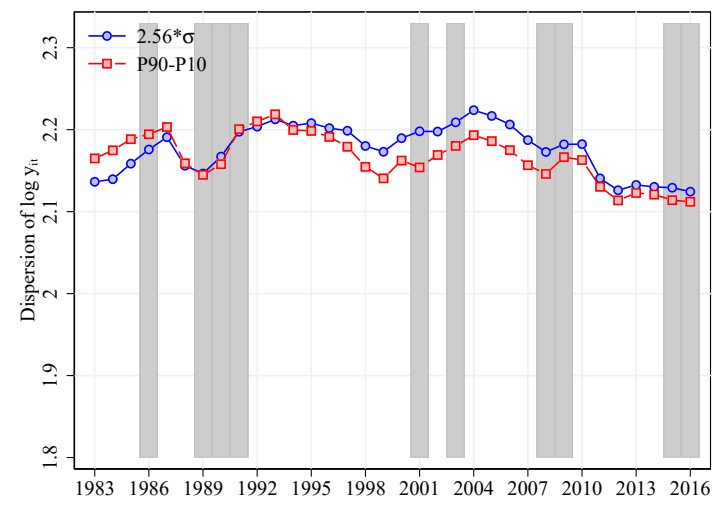

(b) Women

Figure 4: 90-10 percentile difference and $2.56 \times$ standard deviation of $\log \left(y_{i, t}\right)$

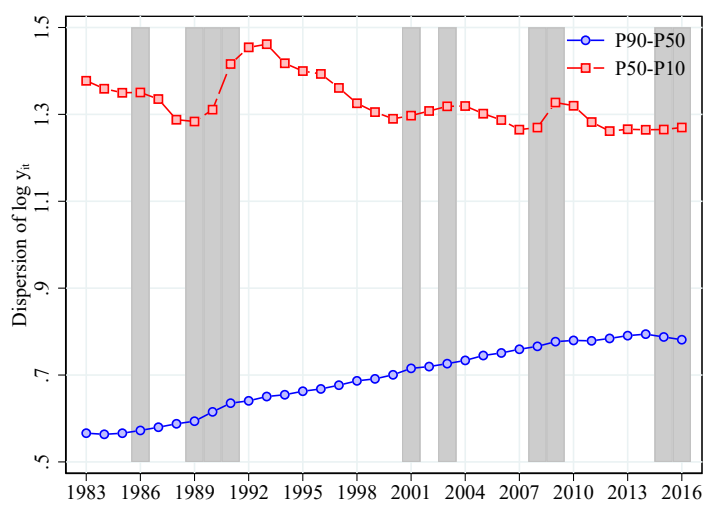

(a) Men

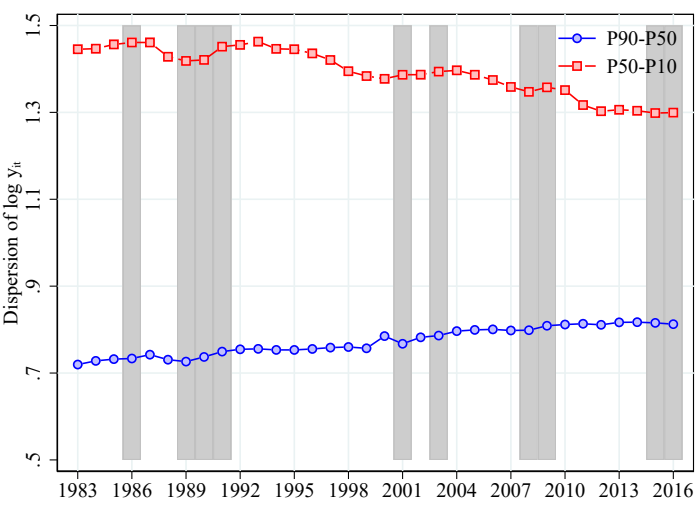

(b) Women

Figure 5: $90-50$ and 50-10 percentile differences for $\log \left(y_{i, t}\right)$

by changes in the age composition of the workforce or by major changes in the variability of year-to-year fluctuations in earnings. The latter point is even more forcefully made by Morissette and Berube (1996), who show that over the early part of our time period (between 1975-84 and 1984-93), the increase in annual earnings inequality was very similar to the increase for 6- and 10-year averages of earnings.

The evolution of earnings inequality for the overall population, combining both men and women, reflects the substantial narrowing of the gender earnings gap, coupled with modest (sometimes opposing) changes within gender. Together, these influences produce time patterns for 90-10, 90-50, and 50-10 log earnings percentile differences that look quite similar to those observed for women (see Appendix Figure A9): overall inequality declined very slightly, reflecting a nearly $20 \log$ point decline in the 50-10 difference and $15 \log$ point increase in the 90-50 difference.

Finally, Table 3 documents the share of earnings earned by each quintile of the earnings distribution (and for top percentiles) in 1985 and 2015, while Figure 6 graphs the changes in these shares relative to their corresponding 1983 values. As might be expected from our previous results, the top quintile of all earners 
increased its share of earnings from $41 \%$ in 1983 to $46 \%$ in 2006, before falling to roughly $45 \%$ after the Great Recession. ${ }^{16}$ These gains came largely at the expense of workers in quintiles 3 and 4, who saw their shares decrease by about 2 percentage points from roughly $18 \%$ and $26 \%$, respectively. As discussed below, the increase for the top quintile comes entirely from increases in the share of earnings among the top 5\%.

Altogether, we find that broad-based measures of earnings inequality changed very little in Canada over the past $35-40$ years, although earnings rose substantially at the very top. ${ }^{17}$

Table 3: Earnings shares (\%) for quintiles and top percentiles (men and women combined), 1985 and 2015

\begin{tabular}{lcclcc}
\hline Earnings Quintiles & 1985 & 2015 & Top Percentiles & 1985 & 2015 \\
\hline Quintile 1 & 4.15 & 4.34 & Top 10\% & 24.97 & 29.48 \\
Quintile 2 & 11.05 & 10.46 & Top 5\% & 15.11 & 19.36 \\
Quintile 3 & 17.88 & 16.16 & Top 1\% & 5.21 & 7.98 \\
Quintile 4 & 25.44 & 23.50 & Top 0.5\% & 3.48 & 5.66 \\
Quintile 5 (top 20\%) & 41.49 & 45.54 & Top 0.1\% & 1.50 & 2.66 \\
& & & Top 0.01\% & 0.46 & 0.86 \\
\hline
\end{tabular}

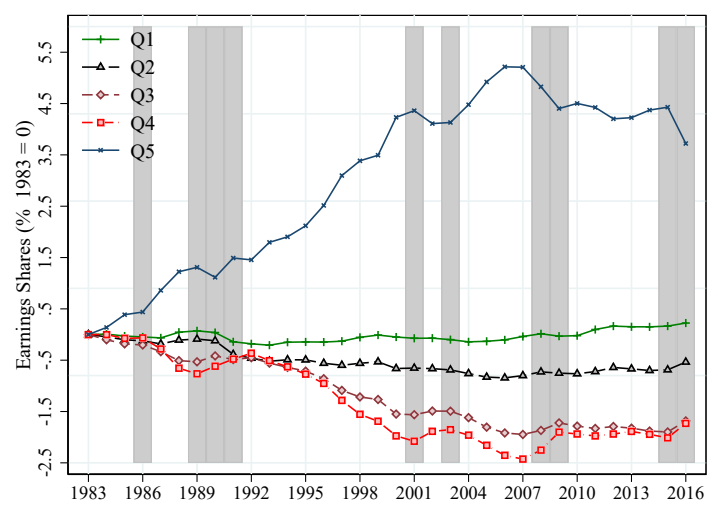

(a) Changes in earnings shares by quintile (1983=0)

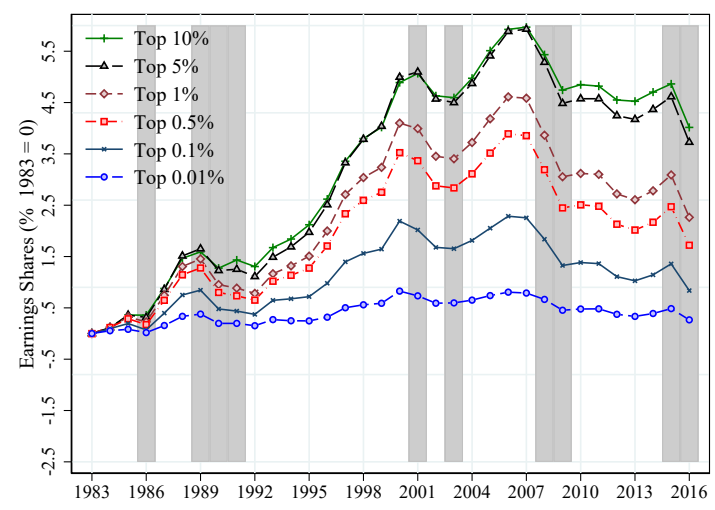

(b) Changes in top earnings shares $(1983=0)$

Figure 6: Changes in earnings shares for $\log \left(y_{i, t}\right)$ for men and women combined $(1983=0)$

Cyclical features. As Figures 2-5 demonstrate, there is considerable cyclicality in earnings inequality, especially for men. ${ }^{18}$ Most notably, the early 1990s recession drove men's earnings at the 10th percentile down more than $20 \%$ over just a few years, while it took more than 5 years for earnings at the bottom of

\footnotetext{
${ }^{16}$ Appendix Figure A12 shows that the Gini coefficient followed a qualitatively similar time pattern, rising from about 0.375 in 1983 to slightly more than 0.42 in 2006 , then falling by about 0.01 after the Great Recession.

${ }^{17}$ Using a measure of per capita household earnings (rather than including men and women separately) and combining data from the Canadian SCF and SLID, Brzozowski et al. (2010) document a stronger increase in the variance of log earnings between 1983 and 2005 but a similar increase in the Gini coefficient relative to our findings reported in Appendix Figures A9 and A12. Our patterns for the evolution of earnings shares in Figure 6(a) are broadly consistent with the Census-based findings of Beach (2016) for 1980-2005.

${ }^{18}$ Brzozowski et al. (2010) show that the cyclical nature of earnings in Canada is driven by cyclicality in both wages and hours of work, both seemingly stronger for men than women over the 1980s and 1990s.
} 
the distribution to (nearly) recover. The Great Recession produced qualitatively similar, but more muted, effects. By contrast, Figure 2(a) shows that men earning at the 75th and 90th percentiles experienced little to no decline during economic downturns. Figure 5(a) shows that the early 1990s recession, and to a lesser extent the Great Recession, generated dramatic increases in the 50-10 difference but negligible impacts on the 90-50 difference for men. Following recessions, the 50-10 difference slowly returned to pre-recession levels, while the 90-50 difference grew at a fairly constant rate through good times and bad. For the most part, these patterns are similar but substantially weaker for women. Figure 5(b) reveals one notable exception: women experienced gradual declines in the 50-10 difference during good times that more than offset the sharp increases during recessions, producing the long-term decline in inequality among women discussed earlier.

As shown in Guvenen et al. (2018), most of these patterns are evident in the U.S. as well, where the 50-10 difference is strongly counter-cyclical while the 90-50 difference is not, and cyclicality is much stronger for men than for women. A notable exception is the sharp increase in the 50-10 difference for American men and women from 2000 to the onset of the Great Recession. By contrast, this measure of inequality at the bottom declined slightly in Canada over this period despite two short economic downturns.

The cyclicality of earnings inequality, especially at the bottom of the distribution, is also apparent for residualized permanent earnings, $\varepsilon_{i, t}^{P}$, as shown in Appendix Figure A7. This finding is broadly consistent with growing recent evidence on the disproportionate impacts of recessions on low-skilled workers (Hoynes, Miller, and Schaller, 2012; Forsythe, 2019; Hershbein and Kahn, 2018). Further evidence on the differential impacts of the early 1990s recession on workers of different skill levels is exhibited in Figure 7, which documents the evolution of 10th, 50th, and 90th percentiles of log earnings residuals over the periods 1988-1998 and 1995-2005 (relative to 1988 or 1995, respectively) separately for different quartiles of recent residualized permanent earnings ( $\varepsilon_{t}^{P}$ measured in 1987 or 1994, respectively). Figures 7(a) and 7(b) show that, among workers with low permanent earnings, inequality grew substantially more during the early 1990s recession relative to the boom period of the late 1990s. Notably, the stronger increase in inequality over the early 1990s recession (for those with low permanent earnings) is driven entirely by a widening at the bottom of the distribution: earnings at the 10th percentile increased much less (or fell much more) through the early 1990s recession than during the later period of sustained economic growth. By contrast, Figure 7(d) shows that residual earnings distributions evolved very similarly across the two periods for workers in the top permanent earnings quartile. Appendix Figure A13 shows qualitatively similar (though more muted) patterns over the Great Recession.

Finally, we draw attention to Figure 3, which shows that among those with earnings in the top $0.1 \%$, earnings are just as cyclical as for workers at the bottom of the distribution. Unlike workers throughout most of the distribution, those at the very top saw their earnings fall more during the Great Recession than during the early 1990s recession. Earnings at the very top also dropped considerably during more modest downturns. This cyclicality at the very top is broadly consistent with findings for the U.S. presented in 


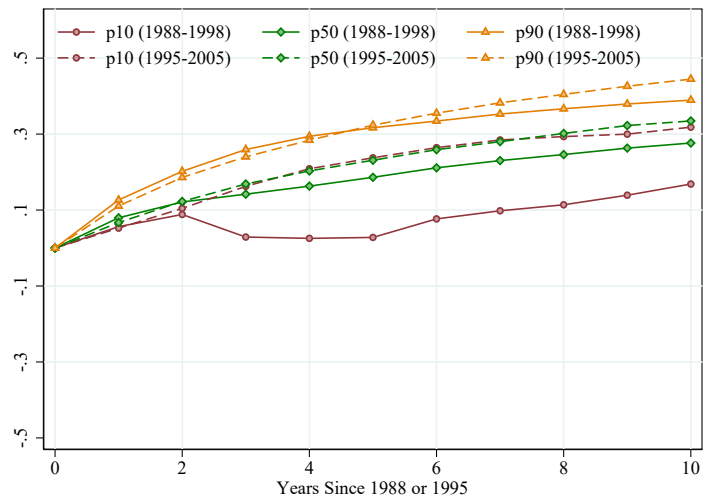

(a) Quartile 1 for $\varepsilon_{i, 1987}^{P}$ (solid) or $\varepsilon_{i, 1994}^{P}$ (dashed)

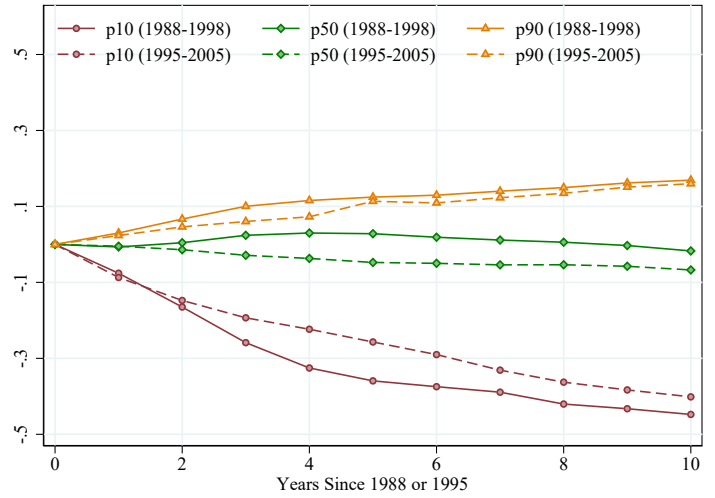

(c) Quartile 3 for $\varepsilon_{i, 1987}^{P}$ (solid) or $\varepsilon_{i, 1994}^{P}$ (dashed)

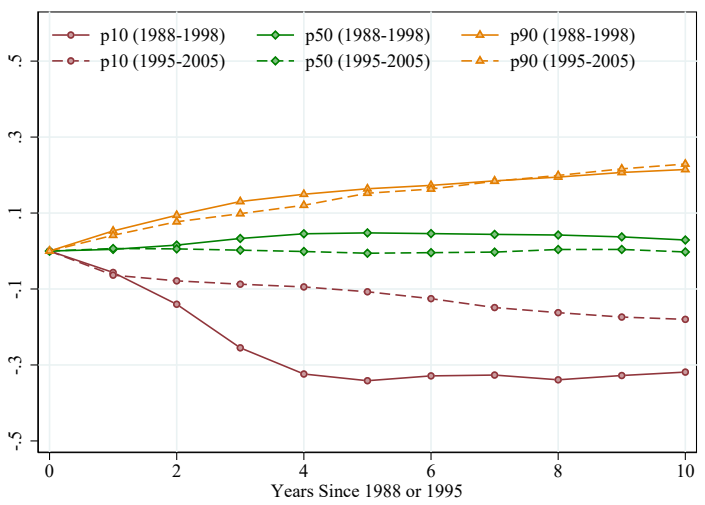

(b) Quartile 2 for $\varepsilon_{i, 1987}^{P}$ (solid) or $\varepsilon_{i, 1994}^{P}$ (dashed)

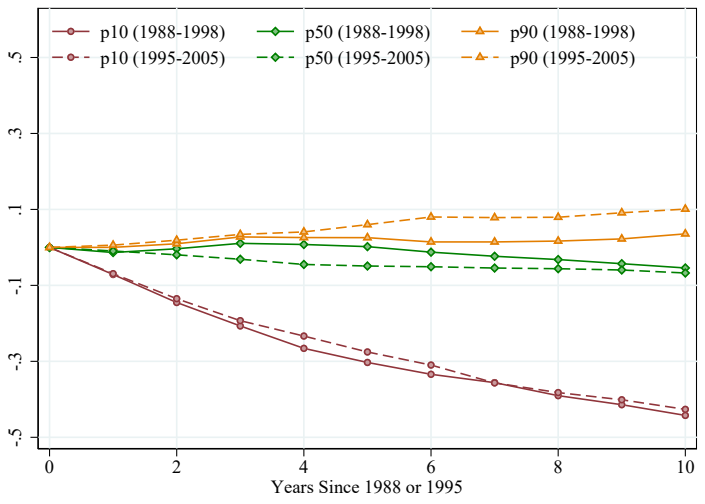

(d) Quartile 4 for $\varepsilon_{i, 1987}^{P}$ (solid) or $\varepsilon_{i, 1994}^{P}$ (dashed)

Figure 7: Changes in percentiles of $\varepsilon_{i, t}$ over 1988-1998 and 1995-2005 by residualized permanent earnings quartile in 1987 or 1994 , respectively

Guvenen, Kaplan, and Song (2014).

Earnings concentration at the very top. Table 3 documents the substantial concentration of earnings at the top of the distribution in Canada. More than a quarter of total earnings goes to the top $10 \%$ of all earners. Between 1985 and 2015, the share of earnings going to the top 1\% rose by 53\% (from 5.2\% to $8.0 \%$ of all earnings), while the share going to the top $0.01 \%$ nearly doubled (from $0.46 \%$ to $0.86 \%$ ). Figure 6 (b) shows that top earnings shares increased until 2007 and then declined afterwards. The short-term fluctuations in top earnings shares are mostly procyclical; however, they have not recovered since the sharp decline during the Great Recession. We can see that most of the rise and fall in the top earnings shares was driven by the top $0.5 \%$ of earners, with earnings shares rising, then falling, for the top $0.1 \%$ and top $0.01 \%$ as well. The share going to those in the top $0.5 \%$ to top $1 \%$ also increased up until the Great Recession, then leveled off, while the share going to those earning from the top $1 \%$ to top $5 \%$ continued rising through 2014 . The share 
going to the top 5\% to top $10 \%$ is counter-cyclical and shows little long-run trend. ${ }^{19}$

Saez and Veall (2005) and Veall (2012) report similar patterns for top income shares in Canada over 1982 to 2010 using the Longitudinal Administrative Data (LAD), a 20\% random sample of all tax filers. Saez and Veall (2005) further show that top income shares in Canada evolved very similarly to those in the U.S. (potentially due to the highly integrated labor market for skilled workers). Moreover, top total income shares are similar to top earnings shares for recent years in Canada, because labor income has become the dominant source of income, even at the very top.

Most recently, the sharp decline in earnings shares for workers in the top 1\% and above in 2016 (see Figure A14) could reflect changes in response to the 2015-2016 economic downturn, although this downturn was quite mild. Alternatively, it could reflect behavioral responses (in labor supply or income reporting for tax purposes) to the 2016 increase in the top marginal income tax rate (from 29\% to 33\%) for those with incomes above $\$ 200,000$. To the extent that tax changes do drive top earnings shares in the short-term, Milligan and Smart (2015) find that they do not explain the long-run trends in Canadian top income shares.

\subsection{Earnings growth and volatility}

We now turn to an analysis of earnings growth rates and earnings volatility (i.e., the dispersion of residual log earnings growth) over time. Variation in earnings growth is of considerable interest, because it reflects individual earnings risk as well as heterogeneity in lifecycle skill growth. Both have important implications for individual consumption/savings decisions and the aggregate distribution of wealth.

A wave of interest in earnings volatility was initially sparked by Gottschalk and Moffitt (1994), who documented an increase in U.S. earnings volatility and variation in transitory earnings shocks over the 1970s and early 1980s. More recently, debate has arisen regarding U.S. trends in volatility over the 1980s and 1990s, with survey-based data suggesting fairly stable (or growing) volatility over time and administrative data suggesting a strong secular decline. See Moffitt (2020) for a review of this literature and efforts to reconcile results across studies and data sources.

Since earnings growth varies strongly over the lifecycle, this analysis focuses on annual and 5-year changes in residualized $\log$ earnings, $\Delta^{1} \varepsilon_{i, t}$ and $\Delta^{5} \varepsilon_{i, t}$, respectively, where the latter are roughly centered around $t$ (i.e., $\left.\Delta^{5} \varepsilon_{i, t}=\varepsilon_{i, t+2}-\varepsilon_{i, t-3}\right){ }^{20}$ In interpreting variation in annual and 5-year growth, it is useful to keep in mind that the former reflects a roughly equal balance of temporary and persistent changes in earnings, while the latter largely reflects the influence of more persistent changes.

As in the previous subsection, we organize much of our discussion around long-term trends and cyclical variation; however, we also provide a more detailed look at the distribution of earnings growth and how it

\footnotetext{
${ }^{19}$ Shares going to, for example, the top $5 \%$ to top $10 \%$ can be determined by looking at the difference between the shares going to the top 10\% and top 5\% in Figure 6(b). See Appendix Figure A14 for the evolution of shares going to various ranges within the top 10\%. Appendix Figure A15 shows that the extreme right tail (top 1\% and top 5\%) of the population earnings distribution shifted further to the right and flattened over time.

${ }^{20}$ The evolution of annual earnings inequality based on arc percent changes is qualitatively similar to that reported here for growth in annual log earnings. Results available upon request.
} 
Table 4: Percentiles of $\Delta^{1} \varepsilon_{i, t}$ and $\Delta^{5} \varepsilon_{i, t}$ for men and women over time

\begin{tabular}{|c|c|c|c|c|c|c|c|c|}
\hline & \multicolumn{4}{|c|}{$\Delta^{1} \varepsilon_{i, t}$} & \multicolumn{4}{|c|}{$\Delta^{5} \varepsilon_{i, t}$} \\
\hline & \multicolumn{2}{|c|}{ Men } & \multicolumn{2}{|c|}{ Women } & \multicolumn{2}{|c|}{ Men } & \multicolumn{2}{|c|}{ Women } \\
\hline & 1985 & 2015 & 1985 & 2015 & 1986 & 2014 & 1986 & 2014 \\
\hline$P 5$ & -0.71 & -0.68 & -0.84 & -0.88 & -0.99 & -1.01 & -1.24 & -1.22 \\
\hline$P 10$ & -0.32 & -0.30 & -0.41 & -0.40 & -0.52 & -0.53 & -0.67 & -0.67 \\
\hline$P 25$ & -0.04 & -0.03 & 0.00 & -0.01 & -0.17 & -0.13 & -0.10 & -0.13 \\
\hline$P 50$ & 0.04 & 0.05 & 0.10 & 0.07 & 0.01 & 0.05 & 0.12 & 0.06 \\
\hline$P 75$ & 0.13 & 0.15 & 0.25 & 0.19 & 0.24 & 0.27 & 0.46 & 0.34 \\
\hline$P 90$ & 0.41 & 0.41 & 0.64 & 0.56 & 0.75 & 0.69 & 1.06 & 0.90 \\
\hline$P 95$ & 0.75 & 0.73 & 1.01 & 0.96 & 1.22 & 1.12 & 1.51 & 1.34 \\
\hline$P 90-P 10$ & 0.73 & 0.72 & 1.05 & 0.97 & 1.27 & 1.23 & 1.72 & 1.56 \\
\hline$P 90-P 50$ & 0.38 & 0.36 & 0.54 & 0.49 & 0.75 & 0.65 & 0.94 & 0.84 \\
\hline$P 50-P 10$ & 0.36 & 0.36 & 0.51 & 0.47 & 0.53 & 0.58 & 0.79 & 0.73 \\
\hline
\end{tabular}

varies with recent earnings levels and age.

Long-term trends. Table 4 reveals very little long-run change in the distribution of annual (5-year) $\log$ earnings growth for men between 1985 and 2015 (1986 and 2014). ${ }^{21}$ Women were much less likely to experience high rates of earnings growth in the more recent period-relative to the early 1980s—with annual (5-year) earnings growth rates declining by as much as 8 (17) $\log$ points at higher percentiles. Not surprisingly, then, we observe little long-term change in earnings volatility for men, but moderate reductions in volatility for women. The 90-10 difference for annual (5-year) log earnings growth among women declines by 8 (16) log points between the beginning and end of our sample, with compression occurring at both the top and bottom of the distribution. Both earnings increases and reductions tended to shrink over time for women, bringing their levels of earnings volatility closer to those of men. Figures 8 and 9 display the full evolution of changes in log earnings growth at different percentiles (all relative to baseline growth rates in 1983) over our sample period. The evolution of annual earnings volatility as measured by the $90-10$ difference or by 90-50 and 50-10 differences are reported in Figures 10 and 11.22

Our findings on the stability of earnings volatility for Canadian men (and very modest declines for women) over the past several decades are largely consistent with the conclusions from most survey-based studies in the U.S. (e.g., see the summary of recent evidence from several different survey-based sudies in Moffitt, 2020); however, this differs greatly from the strong secular declines in volatility documented in studies using American administrative data, which are more directly comparable to our analysis (Sabelhaus and Song, 2010; Guvenen, Ozkan, and Song, 2014; Bloom et al., 2017). For example, Bloom et al. (2017)

\footnotetext{
${ }^{21}$ Our earliest measure of $\Delta^{5} \varepsilon_{i, t}$ is from 1986, which reflects growth in log earnings between 1983 and 1988, while our latest measure is from 2014, which reflects growth in log earnings between 2011 and 2016.

${ }^{22}$ Appendix Figures A16 and A17 show that volatility time patterns are qualitatively similar for analogous measures based on 5 -year log earnings growth rates.
} 


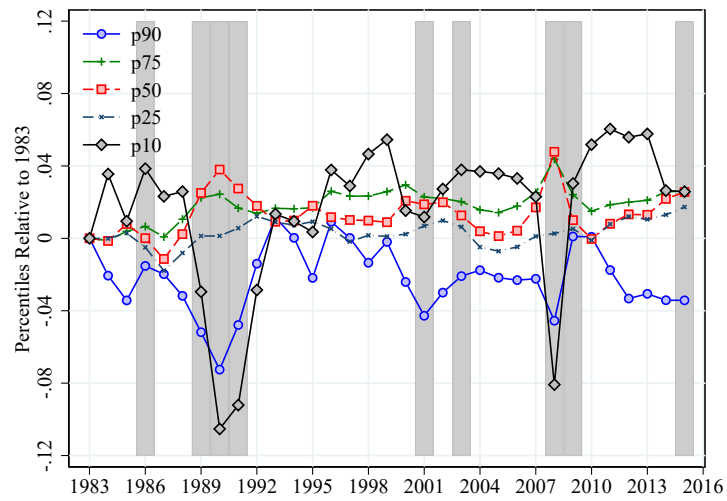

(a) Men

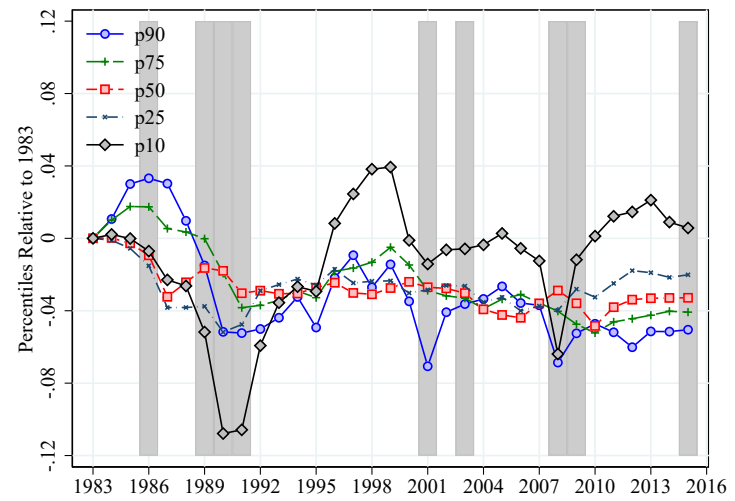

(b) Women

Figure 8: Changes in percentiles of $\Delta^{1} \varepsilon_{i, t}(1983=0)$

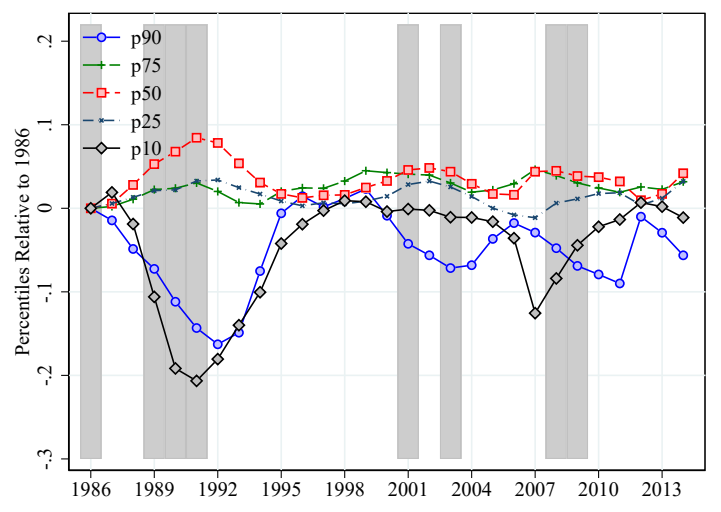

(a) Men

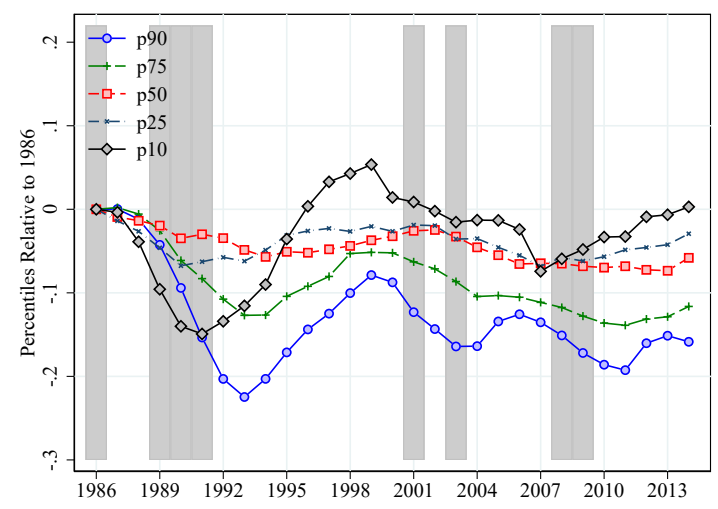

(b) Women

Figure 9: Changes in percentiles of $\Delta^{5} \varepsilon_{i, t}(1986=0)$

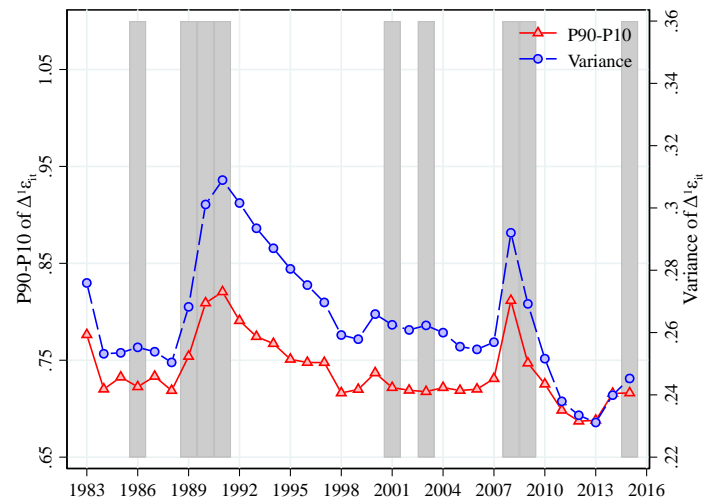

(a) Men

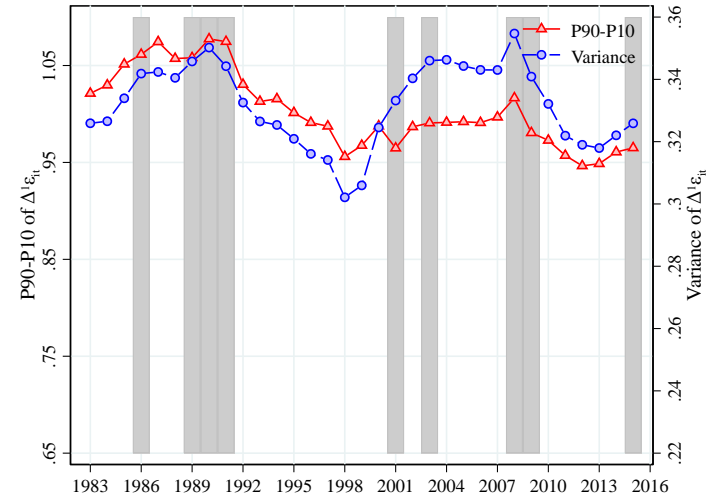

(b) Women

Figure 10: 90-10 percentile difference and variance of $\Delta^{1} \varepsilon_{i, t}$

exploit data from the Social Security Administration and employ similar sampling restrictions to ours. They find that the 90-10 difference in log earnings growth (for both men and women) declined by roughly $30 \log$ 


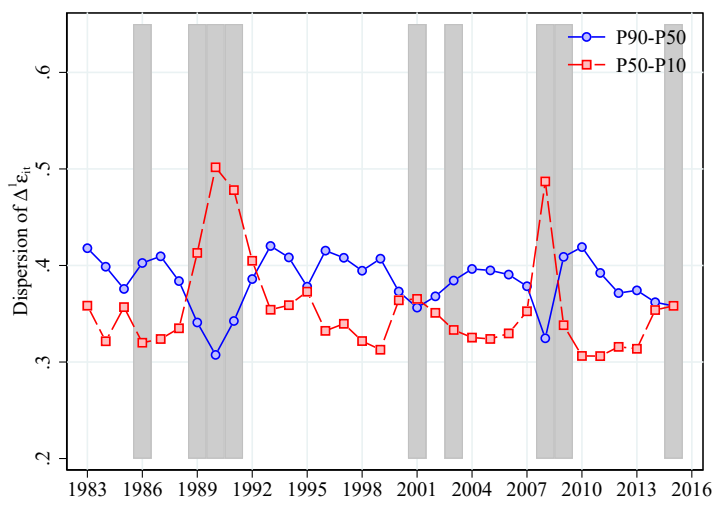

(a) Men

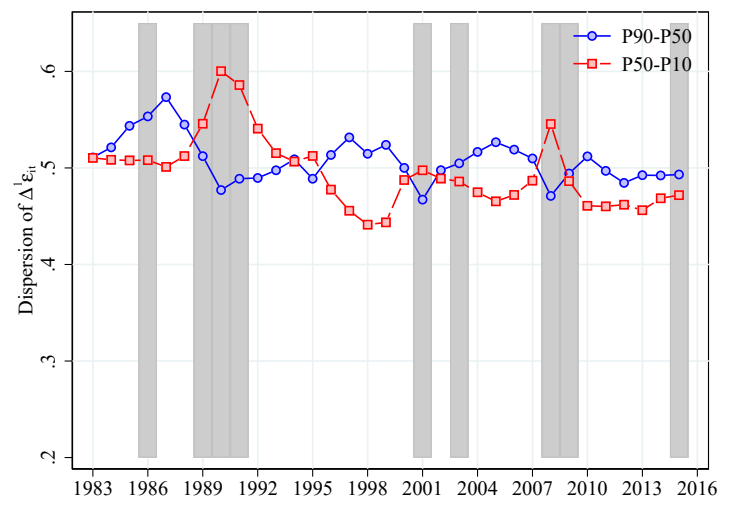

(b) Women

Figure 11: 90-50 and 50-10 percentile differences for $\Delta^{1} \varepsilon_{i, t}$

points between 1983 and 2012 - more than three times the declines we observe over that period.

The skewness of earnings innovations can influence both consumption/savings behavior and asset prices (Mankiw, 1986; Kocherlakota and Pistaferri, 2009). Figure 12(a) reports the evolution of Kelley skewness for $\Delta^{1} \varepsilon_{i, t}$ over time, while the time series for its moment-based coefficient of skewness is reported in Appendix Figure A18(a). ${ }^{23}$ Skewness patterns are quite similar for men and women, and given the discussion so far, it is not surprising to see little long-term trend.

We also explore the kurtosis of log earnings growth distributions, with higher values generally indicating greater mass in the center and tails of distributions relative to the "shoulders". Figure 12(b) reports excess Crow-Siddiqui kurtosis over time, with positive values ranging from 7.5 to 12.0 indicating much stronger kurtosis than implied by a normal distribution (i.e., leptokurtic). Intuitively, this means that earnings growth tends to be very close to zero, with an excess frequency of very high/low growth outliers. While kurtosis appears to have declined slightly for men over the long term, it has substantially risen for women since 2000. As reported in Appendix Figure A18(b), the standard moment-based measure of excess kurtosis also suggests that log earnings growth is leptokurtic; however, it suggests a modest long-run increase in kurtosis for both men and women. ${ }^{24}$

See Appendix A.3 for analogous figures for 5-year log earnings growth dispersion, skewness, and excess kurtosis. To visualize earnings growth distributions and their departures from normality, Appendix A.3 also shows the empirical densities (Figures A21-A22) and log densities (Figures A23-A24) for annual and 5-year residual log earnings growth in 2005 (other years look quite similar). Compared to the best-fitting normal

\footnotetext{
${ }^{23}$ For variable $x$ with mean $\mu$, standard deviation $\sigma$, and 90,50 , and 10 percentiles $P 90, P 50$, and $P 10$, the Kelley skewness measure is $[(P 90-P 50)-(P 50-P 10)] /(P 90-P 10)]$, while the coefficient of skewness is given by $E\left[((x-\mu) / \sigma)^{3}\right]$. Both skewness measures equal zero for symmetric distributions, while positive (negative) values imply that more of the distribution lies to the right (left) of the median or mean.

${ }^{24}$ For variable $x$ with mean $\mu$, standard deviation $\sigma$, and $97.5,75,25$, and 2.5 percentiles $P 97.5, P 75, P 25$, and $P 2.5$, the excess Crow-Siddiqui kurtosis measure is $(P 97.5-P 2.5) /(P 75-P 25)-2.91$, while the moment-based excess kurtosis measure is given by $E\left[((x-\mu) / \sigma)^{4}\right]-3$, where both "excess" measures subtract off the corresponding measure of kurtosis for the normal distribution.
} 
distribution, the distribution of earnings growth has greater mass at the center and tails, with the left tail notably thicker than the right.

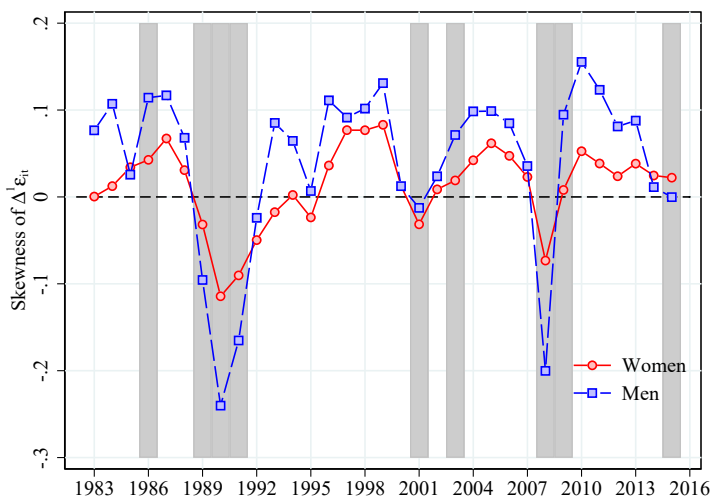

(a) Kelley skewness

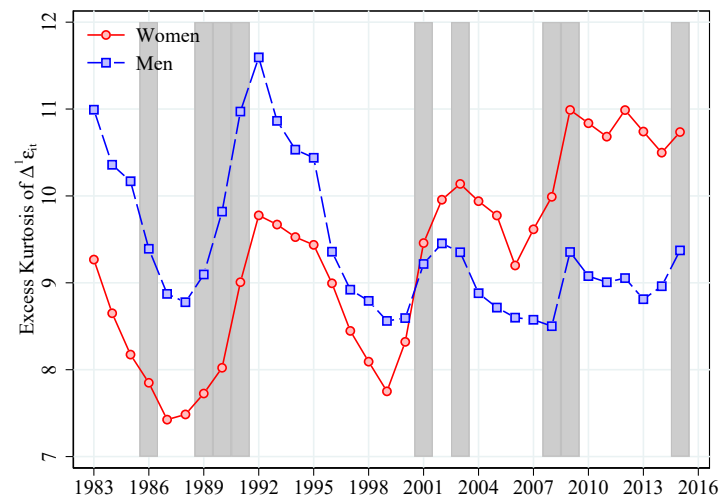

(b) Excess Crow-Siddiqui kurtosis

Figure 12: Skewness and excess kurtosis of $\Delta^{1} \varepsilon_{i, t}$

Cyclical features. As discussed in Guvenen, Ozkan, and Song (2014), the cyclical nature of earnings risk plays an important role in macroeconomic and financial models of consumption/savings and asset prices. We now describe the impacts of major recessions on earnings growth distributions in Canada, including summary features related to earnings volatility, skewness, and kurtosis.

Figures 8 and 9 reveal considerable cyclical variation in log earnings growth at the high (strong positive growth) and low (strong earnings declines) ends of the distribution. Focusing first on men, we observe a modest increase in median earnings growth during recessions, but sizeable reductions in log earnings growth at both the top and bottom. For example, median annual log earnings growth rose by about $5 \log$ points during the early 1990s recession, while low- and high-end annual growth rates dropped by 5-15 log points. Movements in 5-year growth were nearly twice as strong, indicating strong persistent effects of major recessions on earnings for many workers. The cyclical variation in annual log earnings growth for women was quite similar, though slightly more muted at the bottom and middle of the distribution. Changes in five-year log earnings growth over the business cycle were notably different, with much larger and more drawn-out declines in earnings growth at the top compared to the bottom. Indeed, the recessionary declines in 5-year log earnings growth at the top of the distribution were not offset by increases during periods of economic growth, leading to a roughly $15 \mathrm{log}$ point long-term decline. Altogether, we see that Canadian recessions led to sizeable reductions in the prevalence of high earnings growth and increases in the likelihood of severe earnings losses. For men, these changes were reversed during times of economic growth, so there were only modest long-term changes in the distribution of annual or 5-year log earnings growth. This was also true for the distribution of annual log earnings growth among women; however, the female distribution of 5-year growth became much more compressed after the early 1990s recession. 
These patterns imply substantial increases in male earnings volatility during recessions but much weaker increases for women (Figure 10). This counter-cyclical earnings volatility is driven entirely by greater losses at the bottom of the distribution during recessions (exhibited by rising 50-10 differences) and is partially offset by reductions in growth at the top (exhibited by falling 90-50 differences). See Figure 11. Taken together, these patterns imply strong counter-cyclicality of (negative) skewness in log earnings growth as reported in Figure 12(a). Guvenen, Ozkan, and Song (2014) and Bloom et al. (2017) document similar cyclical patterns for skewness in earnings growth in the U.S., but they find less cyclical variation in earnings volatility. ${ }^{25}$ As discussed in Mankiw (1986), Constantinides and Duffie (1996), and recently Guvenen, Ozkan, and Song (2014), the counter-cyclicality of both volatility and (negative) skewness may help explain asset prices and the equity premium puzzle. ${ }^{26}$

Earnings growth and volatility by recent earnings levels and age. Guvenen et al. (2019) find that, among American men, the negative skewness and kurtosis of log earnings growth increase with recent earnings levels and age, arguing that these patterns are broadly consistent with the predictions from job ladder models (e.g., Burdett and Mortensen, 1998; Hubmer, 2018), where large earnings changes are mostly associated with job losses or job switches. Both high earners and older workers have, on average, climbed further up the job ladder, thus there is more room to fall down and experience large earnings drops. The greater chance of large, yet infrequent, earnings losses can lead to more negative skewness and kurtosis in the earnings growth distribution for high-earning, older workers.

We now reproduce these patterns for Canadian men and women. Figure 13 reports the $90-10$ percentile difference for $\Delta^{1} \varepsilon_{i, t}$ by quantiles of (lagged residual) permanent earnings $\varepsilon_{i, t-1}^{P}$ for three age groups. Workers with higher recent earnings generally experience lower dispersion in their future earnings growth, although this relationship is reversed for those with very high permanent earnings. Conditional on permanent earnings, future earnings growth is more variable among younger workers, especially young women. The strong volatility in earnings for young women is largely driven by dispersion at the lower end of the distribution, as is clear from the strong negative skewness for most women ages 25-34 in Figure 14. Interestingly, there is little difference in skewness by age for men or for women ages 35 and over. Skewness is generally declining (or becomes more negative) for workers with higher levels of permanent earnings, although the differences are quite modest for men and older women. Figure 14 also shows excess Crow-Siddiqui kurtosis by age and permanent earnings. This measure of kurtosis is increasing in both age and permanent earnings levels for both men and women in the bottom third of the permanent earnings distribution. At higher permanent earnings levels, kurtosis is largely independent of age for men, while it becomes hump-shaped for women. Except for young women, kurtosis is decreasing in permanent earnings over the upper half of the distribution.

\footnotetext{
${ }^{25}$ Complementary efforts to separately identify transitory and permanent shocks to earnings (in the U.S.) conclude that the variance of transitory shocks is counter-cyclical (e.g., Moffitt and Gottschalk, 2012).

${ }^{26}$ Figure 12(b) suggests that log earnings growth becomes more leptokurtic (as measured by excess Crow-Siddiqui kurtosis) during recessions; however, Appendix Figure A18(b) suggests that kurtosis (based on the standard moment-based measure) declined for men during the early 1990s recession and Great Recession, while there is little apparent cyclicality in kurtosis for women.
} 


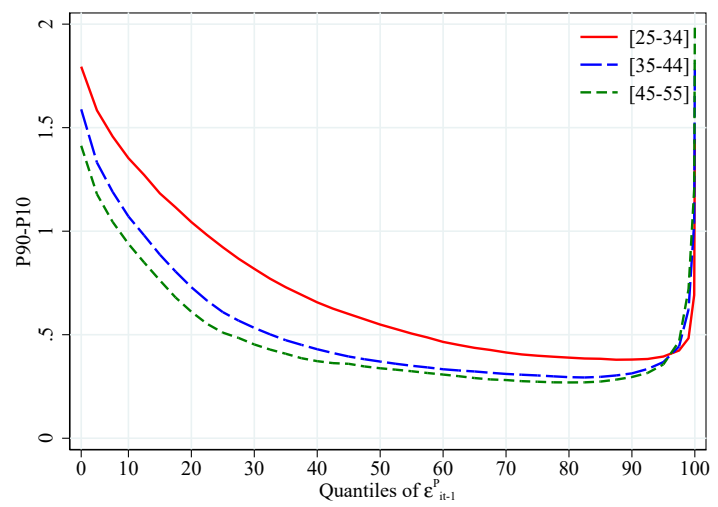

(a) 90-10 percentile difference (men)

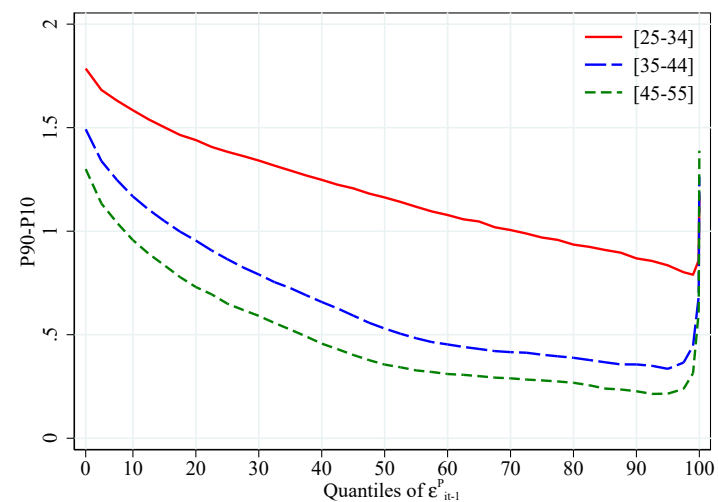

(b) 90-10 percentile difference (women)

Figure 13: $90-10$ percentile difference of $\Delta^{1} \varepsilon_{i, t}$ by permanent earnings and age group

While the dispersion patterns reported in Figure 13 are similar to their U.S. counterparts documented in Guvenen et al. (2019), the skewness and kurtosis patterns in Figure 14 are quite different. Interestingly, our moment-based measures of dispersion, skewness, and kurtosis reported in Appendix Figure A25, as well as measures based on 5-year earnings growth (Appendix Figures A26 and A27), are far more consistent with their findings and standard job ladder models.

\subsection{Earnings mobility}

Another way to study the dynamics of earnings, especially over extended periods of time, is to examine earnings mobility, the likelihood of moving from one part of the earnings distribution to another. Such movements across the distribution speak to whether there is churning across the distribution or stagnation. This is important, because high levels of mobility indicate less inequality in long-run (or permanent) earnings for any given level of cross-sectional inequality in annual earnings. The common rags-to-riches story is one part, but of equal interest is the likelihood of movements down the distribution. The use of transition matrices to study earnings mobility and its effect on long-run inequality was popularized by Buchinsky and Hunt (1999). Bowlus and Robin (2012) use their method to calculate remaining lifetime earnings measures for several countries, finding that Canada has more long-term inequality than the U.S. but less than the U.K. ${ }^{27}$

Here, we examine mobility across distributions of annual log earnings residuals $\varepsilon_{t}$ and our alternative permanent earnings measure $\tilde{P}_{i, t}$. In both cases, we measure relative movements within earnings distributions. We explore mobility across 5- and 10-year time spans for men and women in order to determine the degree to which duration affects mobility_-previous studies often find that mobility levels increase with duration. In addition, we examine mobility across different time periods to see if there have been any changes in the mobility patterns over time in Canada.

\footnotetext{
${ }^{27}$ Long-run inequality can also be studied by using average earnings over a long period of time or by estimating an earnings process with permanent and transitory components. For Canada, an example of the former is Morissette and Berube (1996), while Baker and Solon (2003) is an example of the latter.
} 


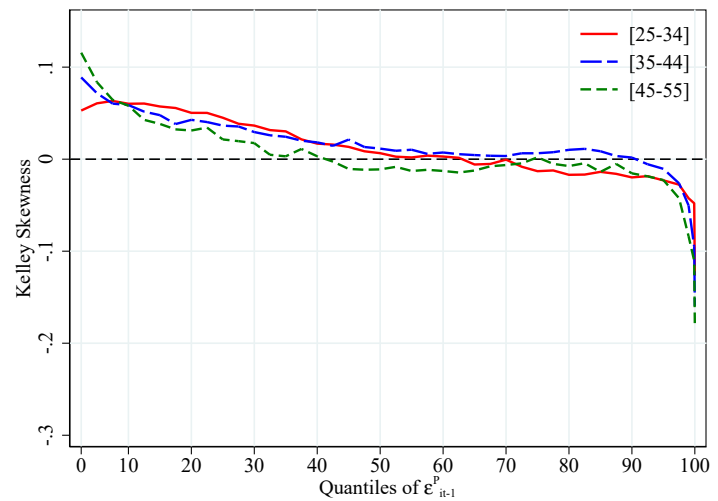

(a) Kelley skewness (men)

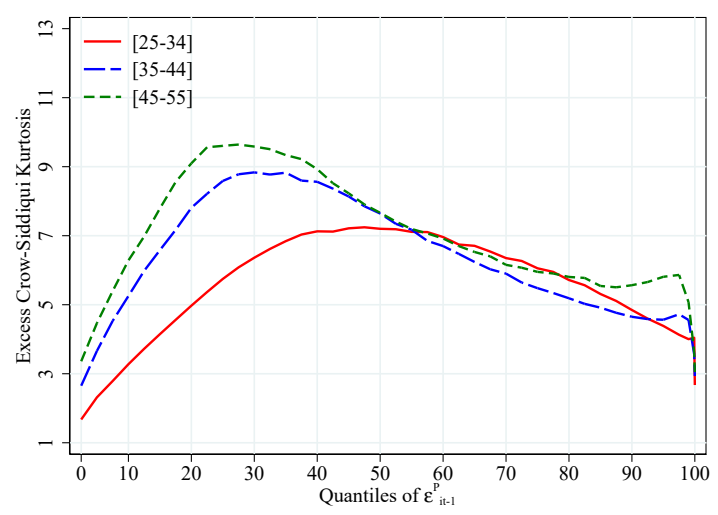

(c) Excess Crow-Siddique kurtosis (men)

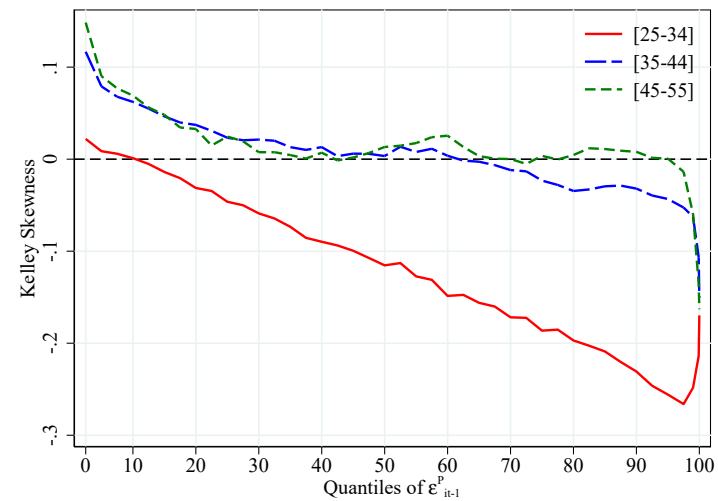

(b) Kelley skewness (women)

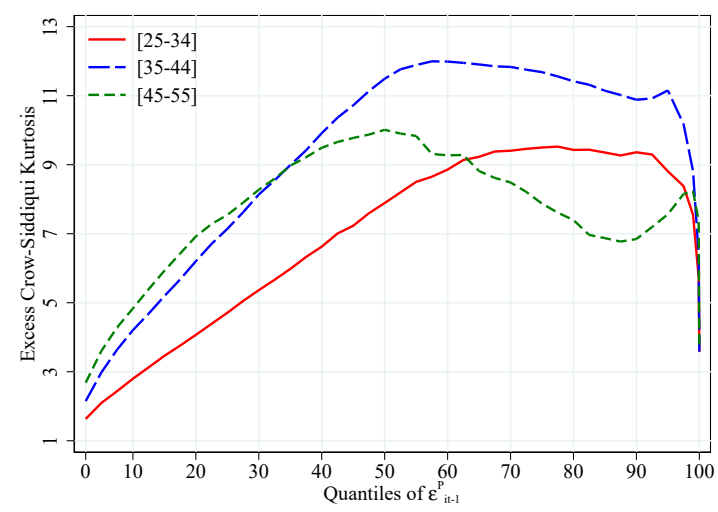

(d) Excess Crow-Siddique kurtosis (women)

Figure 14: Skewness and excess kurtosis of $\Delta^{1} \varepsilon_{i, t}$ by permanent earnings and age group

We begin by studying mobility in annual log earnings residuals $\left(\varepsilon_{t}\right)$ over 1 year and 5 years. Figure 15 shows the average percentile of residuals in the future period for each percentile grouping in year $t=2005$, where percentiles have been grouped into 2.5 percentage point bins along the $\mathrm{x}$-axis. Also shown is the average percentile after 1 year and 5 years for the top $0.1 \%$ of the residual distribution in $t$. As expected, mobility is positive at the bottom of the distribution and negative at the top. Because we are examining mobility within a distribution (i.e., movements across percentiles), there is only one direction to move at each end of the distribution. For both men and women, the cross-over occurs around the 30th percentile for the 1 -year transition and at the 40th percentile for the 5-year transition. This indicates greater upward mobility over a 5-year period for those at the lower end of the residual distribution. Furthermore, the gains are greater at the bottom of the distribution than the losses are at the top. Consistent with much of the literature, mobility is greater over 5 years than 1 year, indicating the importance of mobility for long-run inequality. We also find very little difference in mobility between those in the top 2.5 percentage point bin (97.5-100) and those at the top $0.1 \%$. Appendix Figure A28 reveals very little change between 1985 and 2005 in the 5-year mobility relationships for men and women, except for a slight tilt toward less mobility overall and a small increase in 
mobility at the very bottom of the distribution. ${ }^{28}$

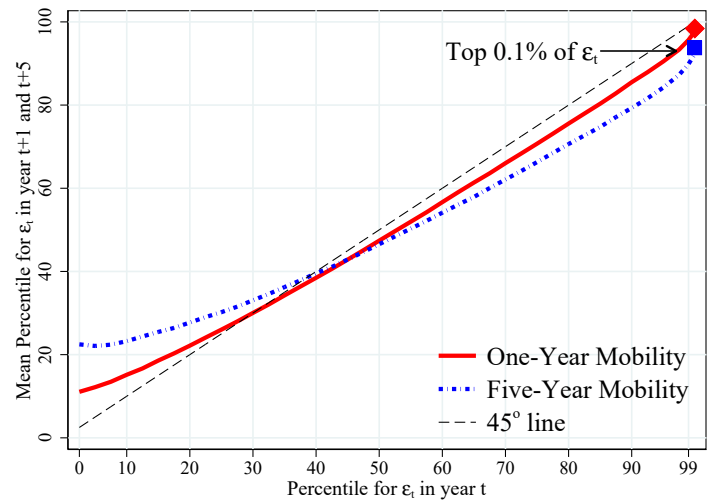

(a) Men

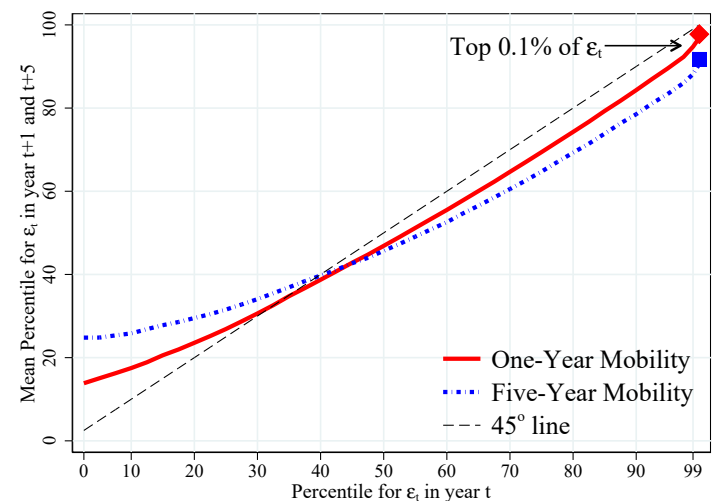

(b) Women

Figure 15: One- and 5-year mobility of residuals $\varepsilon_{i, t}$ for $t=2005$

These findings are similar to other mobility studies for Canada. Using similar tax data, Beach and Finnie (1998) calculate transition matrices across quintiles for 1-year changes, 6-year changes, and 12-year changes from 1982 to 1994, finding that mobility increases with duration between earnings measures. ${ }^{29}$ They also find a decline in the exit rate out of the bottom of the distribution for the more recent years. Lammam, Karabegović, and Veldhuis (2012) provide a more recent analysis of income mobility over the 1990-2009 period, which also finds that mobility increases as the period length increases.

Next, we examine long-term mobility in our alternative permanent earnings measure $\tilde{P}_{i, t}$ (i.e., average earnings over $t-2, t-1$, and $t$, including up to two zero or low earnings levels), which smooths out some of the transitory movements around the distribution. ${ }^{30}$ Figure 16 shows how mobility varies across the alternative permanent earnings distribution by age over a 10-year period. ${ }^{31}$ Figure 16(a) shows the mobility in permanent earnings over 10 years for men who are 25-34 or 35-44 in year $t$, while Figure 16(b) shows the same for women. ${ }^{32}$ The figure shows that 10 -year mobility is decreasing by age for both men and women.

We also examine the evolution of long-term mobility over time for the alternative permanent earnings measure. Figure 17 shows the average $\tilde{P}_{i, t+10}$ by each percentile bin of the $\tilde{P}_{i, t}$ distribution for the years 1985 , 1995, and 2005. (Appendix Figure A30 shows the same changes in 5-year mobility.) The cross-over point for 10-year mobility is around the 40th percentile similar to the cross-over points for residualized annual

${ }^{28}$ The results for 1-year mobility show even less change over this period and are available upon request.

${ }^{29}$ Their earnings measure differs from ours in that it includes net self-employment income in addition to total employment income.

${ }^{30}$ For years in which individuals do not file taxes or indicate zero earnings on their tax return, a value of zero is included in this average. Thus, this earnings measure may reflect extended periods out of the labor force, out of the country, or in unemployment. We have conducted sensitivity analyses which exclude these years of zero earnings by non-filers. The results are virtually identical, suggesting that temporary periods out of the labor force or country are similar to temporary periods of minimal or zero earnings in terms of mobility. These results are available upon request.

${ }^{31}$ This figure graphs the average over all available 10-year periods with initial years from 1985 to 2006 of the average percentile of $\tilde{P}_{i, t+10}$ for each percentile grouping in year $t$ with the percentiles grouped into 2.5 percentage point bins except for the top $0.1 \%$ which has its own bin.

${ }^{32}$ Appendix Figure A29 shows these same patterns for 5-year mobility. 


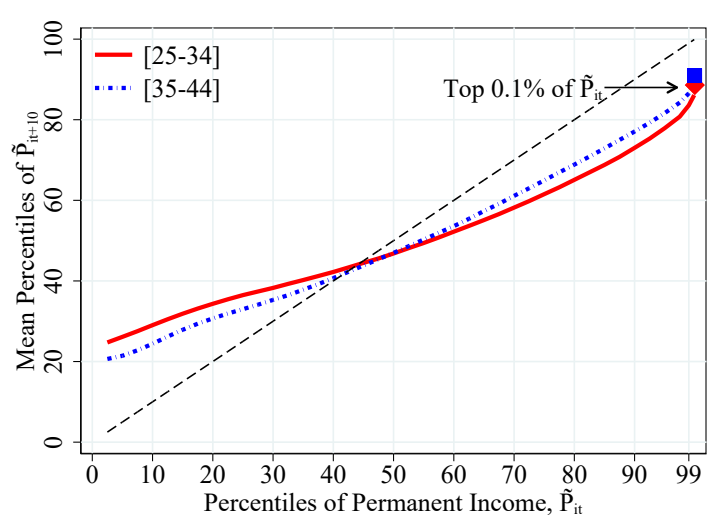

(a) Men

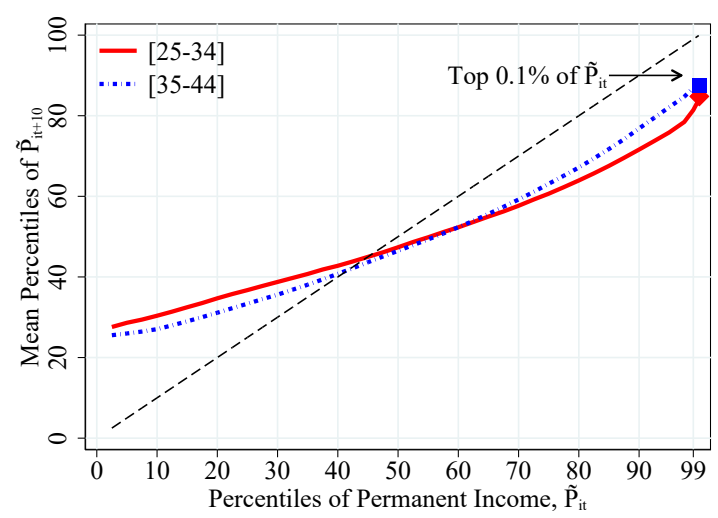

(b) Women

Figure 16: Ten-year mobility in alternative permanent earnings, $\tilde{P}_{i, t}$, by age

earnings. As with residualized annual earnings, there is more mobility (at both the top and bottom of the distribution) after 10 years than 5 years, and those at the top $0.1 \%$ of the distribution do not appear to exhibit different mobility patterns. There is very little change over time in either 5- or 10-year mobility relationships.

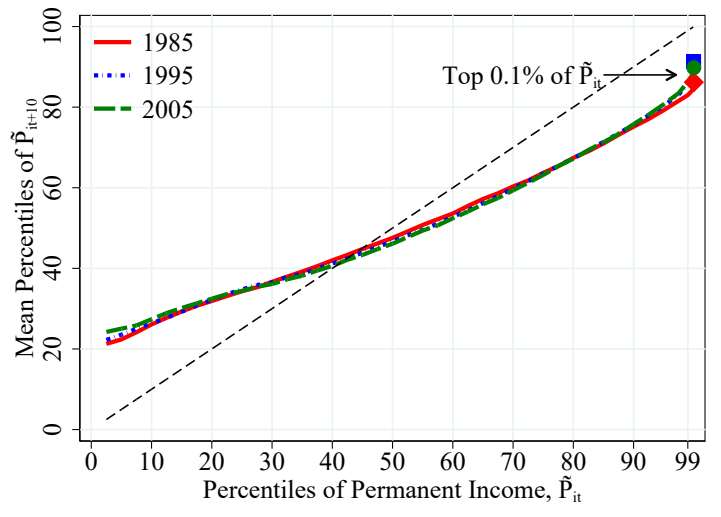

(a) Men

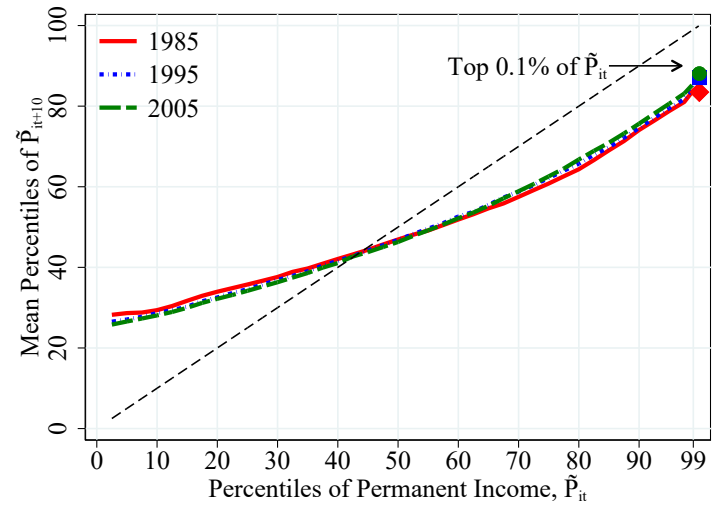

(b) Women

Figure 17: Evolution of 10-year mobility in alternative permanent earnings, $\tilde{P}_{i, t}$, over time

Finally, we examine permanent earnings mobility using $10 \times 10$ decile transition matrices. Table 5 shows 5- and 10-year transitions for 2005 based on the combined sample of men and women using the alternative permanent earnings measure $\tilde{P}_{i, t} \cdot{ }^{33}$ Transition matrices are helpful in understanding the mobility patterns, because they reveal persistence (or lack thereof) along the diagonal and the symmetry (or lack thereof) in terms of upward and downward movements throughout the distribution. Panel (A) of Table 5 shows 5-year transitions starting in 2005. Here, we find greater persistence at the extremes of the distribution than in the middle and more persistence at the top than the bottom of distribution. ${ }^{34}$ In addition, the transition

\footnotetext{
${ }^{33}$ Appendix Table A2 shows 5- and 10-year transitions for 1985. Transition matrices for 1995 are also available upon request.

${ }^{34}$ This finding of higher persistence in the extreme deciles was also found by Bowlus and Robin (2012) for Canada for the 1996-2001 period.
} 
rates are slightly lower just to the right of the diagonal than just to the left. However, it is very unlikely for individuals to make extreme moves out of either tail, with a higher probability of going from the 10th decile to the 1st than the 1st to the 10th. Panel (B) of Table 5 shows the transition matrix for 10-year changes. As expected, the transition rates along the diagonal are substantially reduced compared to 5-year changes, indicating greater mobility over 10 years than 5. However, there remains strong persistence at the top, with $50 \%$ of those in the top decile remaining there 10 years later. In comparison, less than $35 \%$ of those in the bottom decile are still there after 10 years. ${ }^{35}$ By comparing Table 5 and Appendix Table A2, we again see that little has changed over time, although there does appear to be a pattern of declining persistence in the middle of the distribution, with a modest increase in downward mobility. This decline in persistence is not observed at the top or bottom of the distribution. Further, the likelihood of going from the very bottom decile to the top two deciles (i.e., 'rags to riches') has almost doubled for the 5-year change (this increase is also present, but weaker, for the 10-year change).

Table 5: Transitions across Deciles for $\tilde{P}_{i, t}$ over 5 and 10 Years Starting in 2005

\begin{tabular}{|c|c|c|c|c|c|c|c|c|c|c|}
\hline \multicolumn{11}{|c|}{ (A) Five-year mobility } \\
\hline$t$ & decile 1 & decile 2 & decile 3 & decile 4 & decile 5 & decile 6 & decile 7 & decile 8 & decile 9 & decile 10 \\
\hline decile 1 & 40.1 & 22.9 & 13.5 & 8.2 & 5.1 & 3.6 & 2.7 & 1.9 & 1.2 & 0.8 \\
\hline decile 2 & 22.5 & 26.3 & 18.2 & 11.7 & 7.6 & 5.3 & 3.6 & 2.5 & 1.5 & 0.8 \\
\hline decile 3 & 12.9 & 19.0 & 23.1 & 16.1 & 10.5 & 7.0 & 5.0 & 3.5 & 2.0 & 1.0 \\
\hline decile 4 & 8.2 & 11.2 & 18.1 & 22.2 & 15.2 & 10.1 & 6.6 & 4.3 & 2.8 & 1.4 \\
\hline decile 5 & 5.4 & 7.4 & 10.2 & 19.2 & 23.4 & 14.3 & 9.4 & 5.8 & 3.2 & 1.7 \\
\hline decile 6 & 3.8 & 5.1 & 6.6 & 9.7 & 20.7 & 23.9 & 14.3 & 9.0 & 4.8 & 2.1 \\
\hline decile 7 & 2.7 & 3.5 & 4.4 & 5.8 & 8.9 & 21.9 & 25.7 & 15.5 & 8.3 & 3.2 \\
\hline decile 8 & 2.0 & 2.3 & 3.1 & 3.5 & 4.8 & 8.3 & 22.7 & 29.7 & 17.4 & 6.2 \\
\hline decile 9 & 1.4 & 1.4 & 2.0 & 2.3 & 2.5 & 3.9 & 7.4 & 22.7 & 39.6 & 16.9 \\
\hline decile 10 & 1.1 & 0.9 & 1.0 & 1.3 & 1.4 & 1.7 & 2.6 & 5.1 & 19.2 & 65.8 \\
\hline \multicolumn{11}{|c|}{ (B) Ten-year mobility } \\
\hline$t$ & decile 1 & decile 2 & decile 3 & decile 4 & decile 5 & decile 6 & decile 7 & decile 8 & decile 9 & decile 10 \\
\hline decile 1 & 32.1 & 21.5 & 14.1 & 9.4 & 6.6 & 5.0 & 4.0 & 3.2 & 2.3 & 1.7 \\
\hline decile 2 & 21.2 & 22.0 & 16.6 & 11.8 & 8.5 & 6.5 & 5.0 & 3.9 & 2.7 & 1.8 \\
\hline decile 3 & 14.0 & 18.4 & 18.5 & 14.3 & 10.5 & 8.0 & 6.2 & 4.7 & 3.3 & 2.1 \\
\hline decile 4 & 9.6 & 12.4 & 17.6 & 17.2 & 13.3 & 9.9 & 7.6 & 5.7 & 4.2 & 2.5 \\
\hline decile 5 & 6.9 & 8.5 & 12.4 & 18.6 & 16.5 & 12.7 & 9.7 & 6.9 & 4.9 & 2.9 \\
\hline decile 6 & 5.1 & 6.1 & 7.9 & 13.1 & 19.1 & 16.2 & 12.8 & 9.4 & 6.6 & 3.6 \\
\hline decile 7 & 3.9 & 4.4 & 5.2 & 7.1 & 13.5 & 19.8 & 17.4 & 13.7 & 9.8 & 5.1 \\
\hline decile 8 & 2.9 & 3.2 & 3.6 & 4.2 & 6.5 & 13.6 & 21.0 & 20.4 & 16.0 & 8.5 \\
\hline decile 9 & 2.3 & 2.1 & 2.6 & 2.6 & 3.5 & 5.8 & 12.2 & 23.9 & 27.4 & 17.5 \\
\hline decile 10 & 2.0 & 1.4 & 1.5 & 1.6 & 1.8 & 2.5 & 4.0 & 8.3 & 22.7 & 54.2 \\
\hline
\end{tabular}

Notes: Each entry reflects the probability of moving from the decile reported for that row to the decile reported for the column.

\footnotetext{
${ }^{35}$ One reason for this pattern is likely upward movement due to lifecycle skill accumulation or career progression, as these measures do not remove age effects.
} 


\subsection{Inequality by age and cohort}

A decades-long literature on wage and earnings inequality documents worsening wage and earnings outcomes for younger relative to older workers over time (see, e.g., the survey in Acemoglu and Autor, 2011). More recently, Hoynes, Miller, and Schaller (2012) highlight the stronger adverse employment effects of recessions on younger and less-skilled workers. Beaudry and DiNardo (1991) show that, consistent with implicit contracting models, poor labor market conditions appear to have lasting effects on wages, while Jacobson, LaLonde, and Sullivan (1993) demonstrate the lasting effects of job displacement on earnings. Numerous subsequent studies confirm these basic findings. Taken together, these results suggest that recessions are likely to reduce the earnings of younger workers more than older workers and that they may differentially distort the lifecycle patterns of workers from different cohorts.

In Figure 18, we plot the median, 10th percentile, and 90th percentile of log earnings for men and women at ages 25, 30, and 35, along with the observed lifecycle trajectories for cohorts that were age 25 in 1985, 1990,..., 2010. The long-term trends for workers ages 30 or 35 largely agree with our earlier results (see Figure 2), showing that median earnings were stagnant for men and rising for women, while earnings at the 10th and 90th percentiles rose for both men and women. By contrast, earnings for 25-year-old workers changed very little over the long term, even falling slightly at the median for both genders.

The early 1990s recession had a devastating impact on the earnings of 25 -year-old men and women but much smaller effects on workers who were 30 years old at the time, although 30 -year-olds at the 10th percentile certainly felt the impacts. Earnings of 35-year-olds at the median and 90th percentile experienced almost no visible effects on their earnings through any of the Canadian recessions, while the early 2000s downturns and the Great Recession produced modest earnings reductions for those at the 10th percentile. These results are generally consistent with the stronger effects of recessions on low-skilled workers documented by Hoynes, Miller, and Schaller (2012).

Guvenen et al. (2018) document a similar decline in the early 1990s and rise in the late 1990s for median earnings among 25-year-old men; however, the decline is noticeably more pronounced among 35-year-old American men compared to Canadian men. Differences between Canadian and American women are more noteworthy. While 25-year-old Canadian women saw close to $30 \mathrm{log}$ point drops in their median earnings over the early 1990s, followed by a protracted partial recovery over the next 15 years, young American women experienced only modest declines in median earnings over the early 1990s, followed by a sharp increase during the late 1990s and subsequent decline. Median earnings increased slowly and consistently over time for 35-year-old Canadian women, while they increased sharply over the late 1990s and then remained flat thereafter for American women. These comparisons highlight the strength of the early 1990s recession in Canada and tepid recovery over the late 1990s, especially for young Canadian women.

As most economic models predict, the lifecycle profiles plotted in Figure 18 are generally increasing and concave, especially those at the 90th percentile, which show little disruption due to business cycles. We also see less lifecycle growth for women throughout the distribution and over time. The impacts of recessions on 


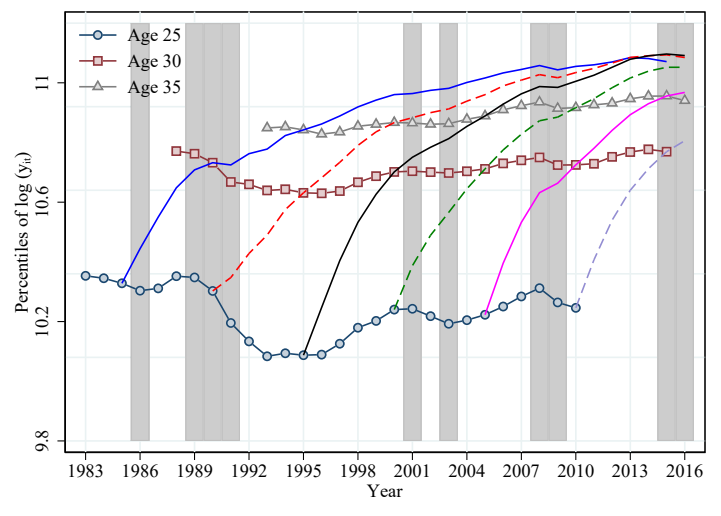

(a) Median (men)

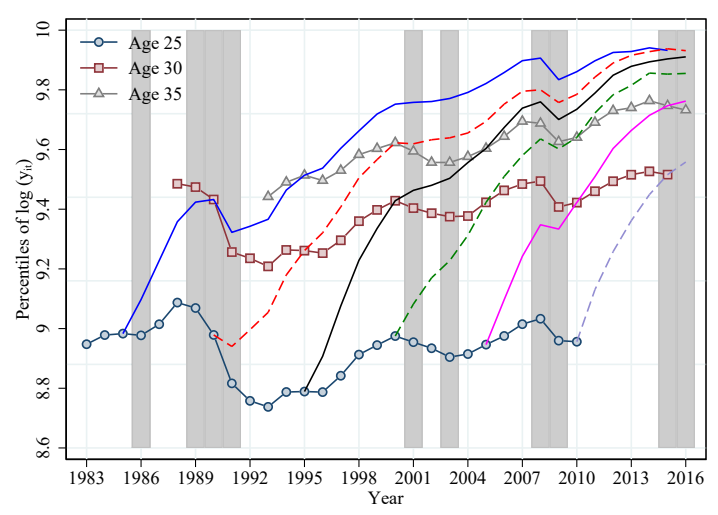

(c) 10th percentile (men)

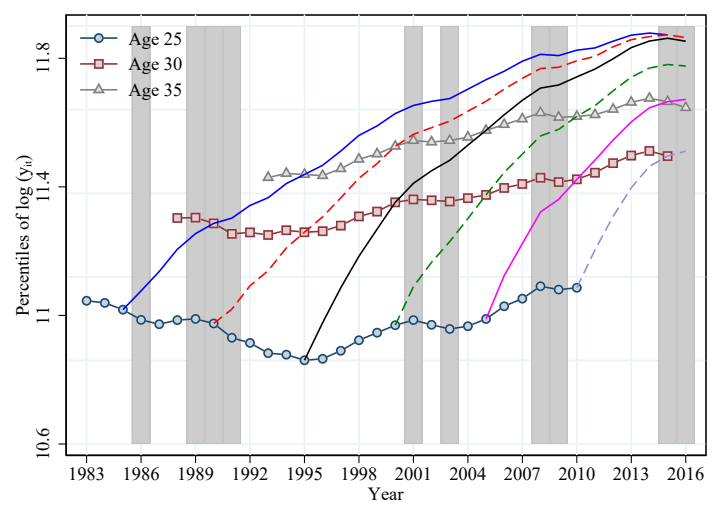

(e) 90th percentile (men)

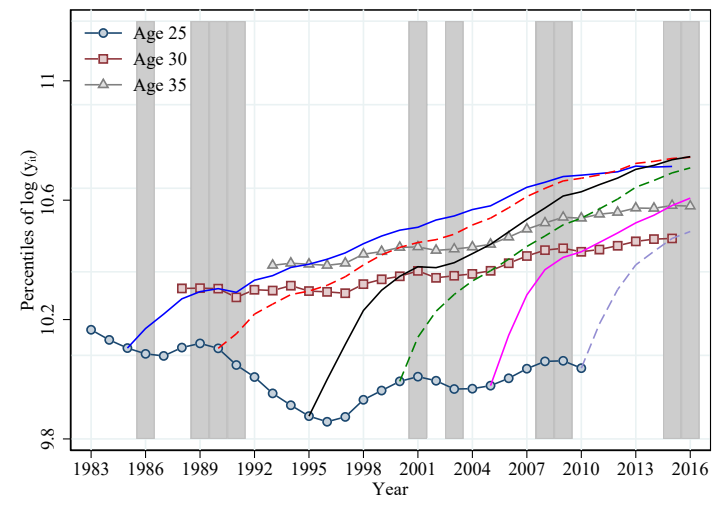

(b) Median (women)

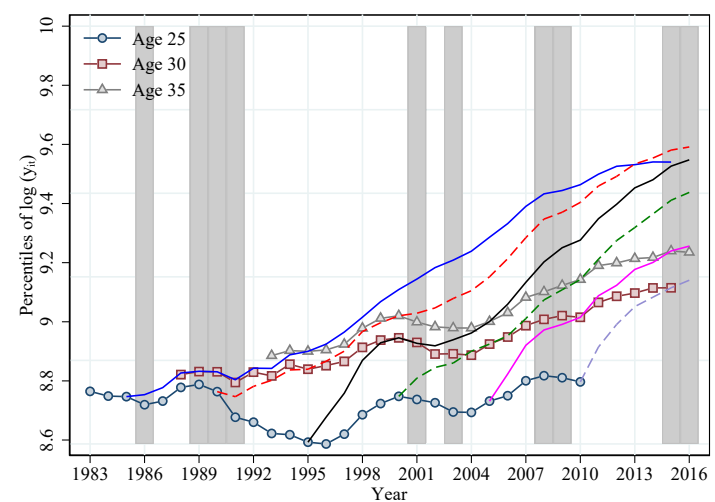

(d) 10th percentile (women)

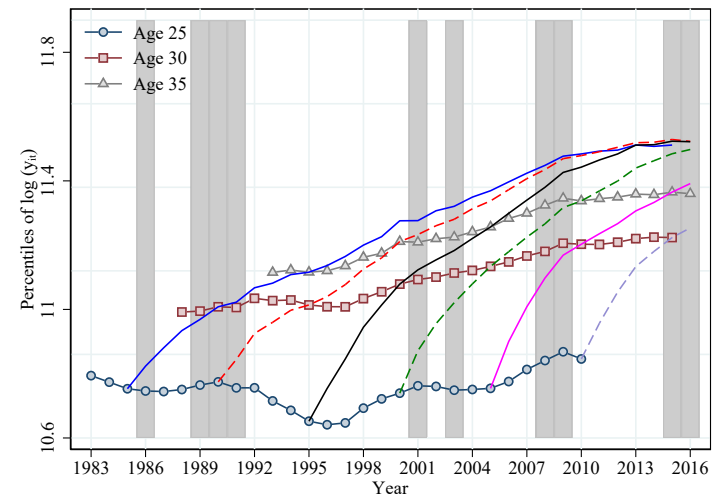

(f) 90 th percentile (women)

Figure 18: Age and cohort profiles for median, 10th, and 90th percentiles of $\log \left(y_{i, t}\right)$

lifecycle profiles are most stark at the bottom of the earnings distribution, where the early 1990s recession, as well as the Great Recession, led to modest declines in earnings for men from all cohorts. Any lingering effects on earnings for cohorts that were young during the depths of recessions appear to be modest, at best. For example, we see fairly rapid log earnings growth over ages 25-30 for the cohort of 25-year-olds in 1995 
compared to the cohort turning age 25 five years earlier or later. The effects of contemporaneous economic conditions on earnings are clearly dominant.

The implications of these patterns for inequality (as measured by 90-10 percentile differences) across cohorts (at ages 25, 30, and 35), as well as over the lifecycle for various cohorts, are shown in Figure 19. Inequality rises quickly during recessions and falls more slowly during booms, whether we follow a given cohort as they age or look across cohorts at a specific age. Among men, the evolution of inequality over the lifecycle is driven largely by aggregate economic conditions, while we observe a clear tendency for inequality to rise over the early part of women's careers and fall later in their careers.

Figure 20 focuses on inequality at ages 25 and 35 across cohorts, showing 90-50 and 50-10 percentile differences in addition to the 90-10 difference. As with our earlier findings for the full sample (Figures 4 and 5), the long-run stability of the 90-10 difference reflects an offsetting increase in the 90-50 difference and decline in the 50-10 difference. The cyclicality of inequality is strongest for younger workers-especially young men-driven by changes at both the top and bottom of the earnings distribution. Among 35-year-old men, inequality only increases at the bottom of the earnings distribution during recessions, while inequality at the top of the distribution is largely immune to the cycle. Inequality among 35 -year-old women is also largely acyclical. It is noteworthy that the early 1990 s recession led to greater increases in inequality for men of all ages compared to women.

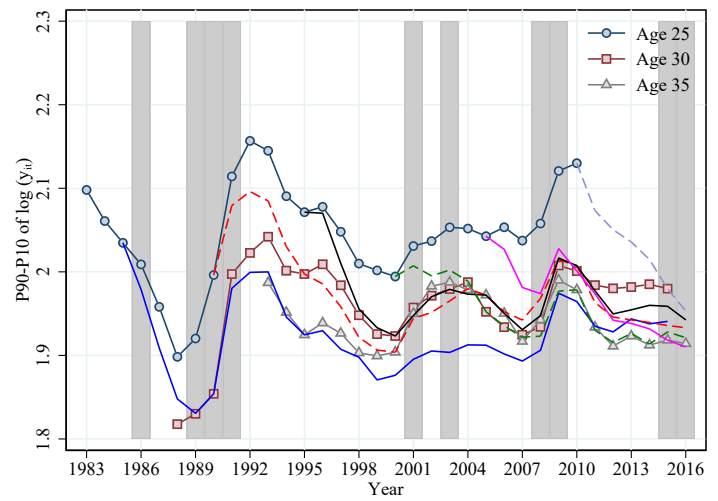

(a) Men

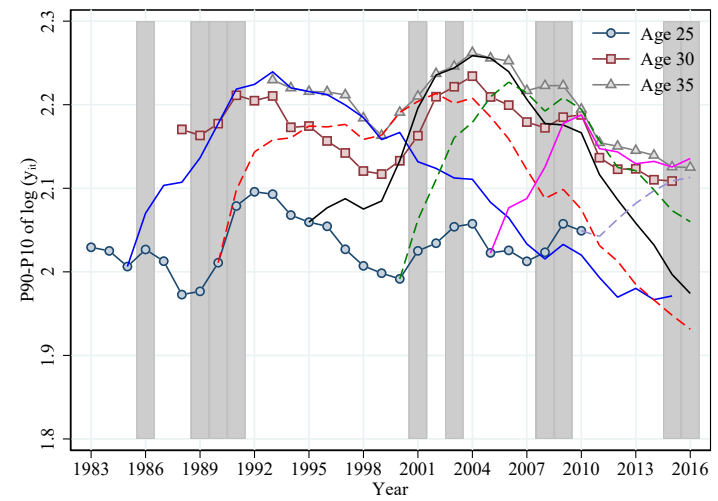

(b) Women

Figure 19: Lifecycle inequality (90-10 percentile differences) in $\log \left(y_{i, t}\right)$ across cohorts

Our long time series can help distinguish between cohort differences in lifecycle profiles that are driven mostly by (sometimes protracted) business cycle effects and longer-term trends. To appreciate this, consider that Beaudry and Green (2000) exploit SCF data from 1971-1993, while Beach and Finnie (2004) use LAD tax data from 1982-1999 to study cohort lifecycle profiles. Together, they document an upward shift in earnings profiles for cohorts entering in the 1960s and 1970s, followed by downward shifts for those entering in the 1980s and early-1990s. Throughout the 1980s, lifecycle profile shifts remained largely parallel; however, they appear to have steepened for cohorts entering in early 1990s. Although we do not observe 


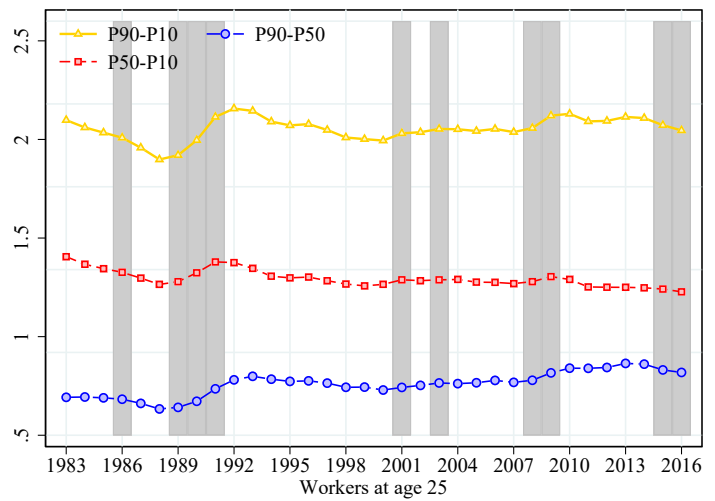

(a) Age 25 men

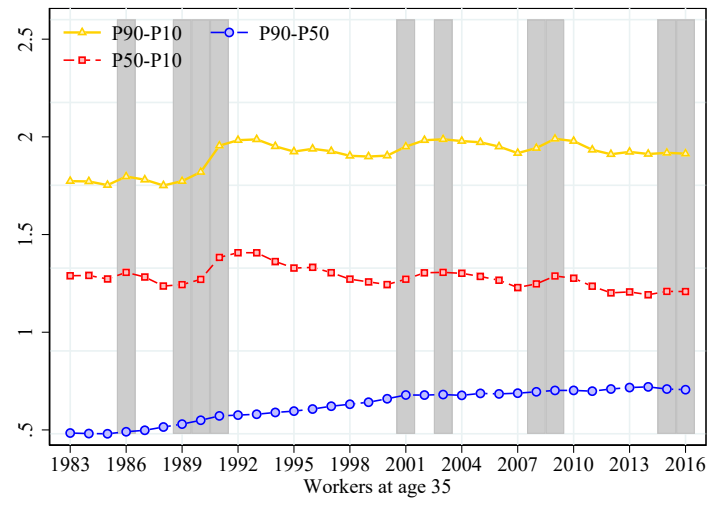

(c) Age 35 men

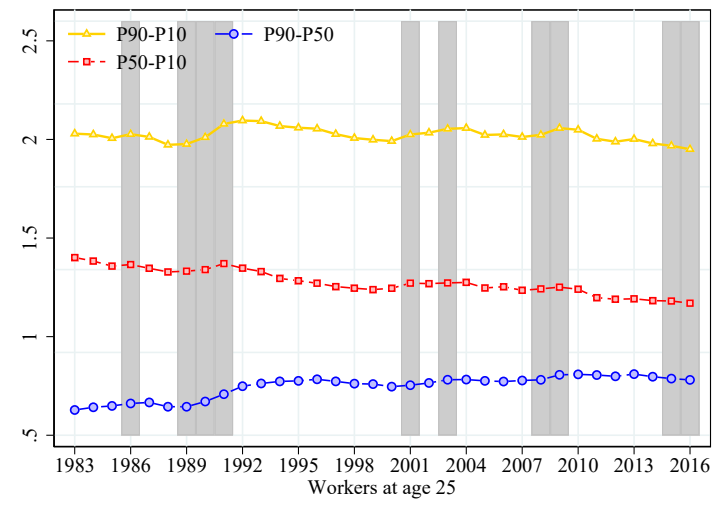

(b) Age 25 women

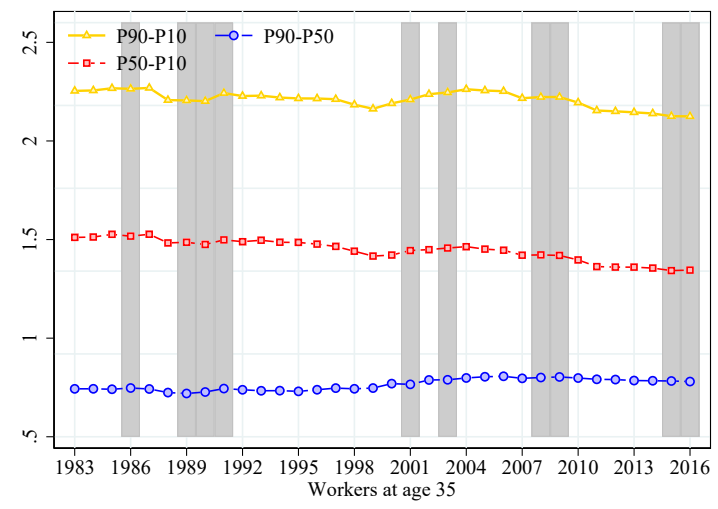

(d) Age 35 women

Figure 20: 90-10, 90-50, and 50-10 percentile differences for $\log \left(y_{i, t}\right)$ by age and gender

cohorts entering in the 1970s, our profiles are generally consistent with their findings over the 1980s and 1990s. Yet, it is also clear from our analysis that the patterns observed for cohorts entering over the late 1980s and early 1990s do not represent long-term shifts in earnings profiles. Instead, they reflect the devastating and drawn-out impacts of the early 1990s recession. Earnings profiles shifted back up in the late 1990s and changed little for cohorts turning age 25 between 2000 and 2010.

\section{The Role of Firm Dynamics}

As discussed in the previous section, recessions are associated with large and persistent changes in earnings dynamics for workers. In Canada's early 1990s recession, male employment rates fell by roughly 5 percentage points (see Figure 1). Over that same period, there was a large and persistent decline in earnings across much of the earnings distribution, coupled with a sharp and sustained increase in the dispersion and (negative) skewness of earnings growth (see Figures 2, 10, and 12(a)).

Motivated by these observations, we now examine whether similar patterns appear at a more micro level-within firms. That is, we explore the relationship between firm-level employment dynamics and the 
individual-level earnings dynamics of workers at those firms, breaking down the analysis between workers who change employers (i.e., movers) and those who remain at the same employer (i.e., stayers). Our empirical evidence is particularly well-suited to discipline structural models of earnings dynamics that incorporate firm dynamics. Regarding this point, an active literature studies models of hiring and wage-setting in the labor market where firms experience stochastic shocks that lead them to grow or shrink over time (e.g., Kaas and Kircher, 2015; Coles and Mortensen, 2016; Gouin-Bonenfant, 2018; Bilal et al., 2019; Elsby and Gottfries, 2019). However, there is limited evidence — beyond the literature on the wage-productivity pass-through—on how the earnings of workers correlate with the employment dynamics of their employers.

We first describe the data that we use and then document a number of empirical regularities.

\subsection{The matched employer-employee sample: 2001-2016}

As discussed in Section 2, the CEEDD links several firm-level administrative data files to the worker-level T1PMF tax file that we have used thus far. We now briefly describe the four main data sources that we use for our analysis of worker and firm dynamics. First, we use corporate tax returns (T2), which include financial information that allows us to construct our measure of firm-level value-added. Second, we use payroll records (PD7) to obtain our measure of annual employment (i.e., firm size). Third, we use employment records (ROE) to obtain our measure of layoffs. Finally, we use business register (BR) data to obtain information on the age and industry of firms. These files are available from 2001 to 2016.

Sample restrictions. We restrict the sample to private sector firms (i.e., all businesses except those in public administration, education, and health care) that are incorporated and have at least 5 employees. We focus on incorporated firms in order to have financial information (only corporations file a T2). We focus on firms with at least 5 employees so that our measure of annual employment growth has a reasonable distribution. ${ }^{36}$ To construct the matched employer-employee sample, we start from the set of worker-year observations that satisfy the sample restrictions described in Section 2. We match each of these observations with their "main employer", defined as the employer which was the largest source of labor earnings throughout the year.

Table 6 contains summary statistics for the first and last year of the sample, both for our restricted sample, as well as for the full sample (i.e., all firms and workers). The restricted sample contains roughly $30 \%$ of all firms and roughly $60 \%$ of all employees. Firms in the restricted sample tend to be larger, and workers tend to have higher annual earnings. Moreover, women are under-represented in the restricted sample.

Variable definitions. In all subsequent analysis, we define earnings growth as the change in residual log annual earnings between year $t$ and $t+1$ (i.e., the variable defined as $\Delta^{1} \varepsilon_{i, t}$ earlier). Note that, while we match workers to their "main employer", our measure of annual earnings corresponds to the sum of earnings from all jobs held throughout the year. We estimate how the mean and dispersion of earnings growth vary

\footnotetext{
${ }^{36}$ For example, the addition of one new worker to a one- or two-person firm implies $100 \%$ or $50 \%$, respectively, increases in employment.
} 
Table 6: Matched sample: summary statistics

\begin{tabular}{llccccccc}
\hline & & \multicolumn{2}{c}{ Firms } & & \multicolumn{4}{c}{ Employees } \\
\cline { 3 - 4 } \cline { 7 - 8 } Year & Sample & Observations & Employment & & Observations & Age & Annual earnings & \% Women \\
\hline 2001 & Full & 758,031 & 16.27 & & $9,689,005$ & 39.98 & 52,687 & 48.54 \\
2001 & Restricted & 208,203 & 38.62 & & $6,024,677$ & 39.41 & 56,044 & 40.48 \\
2016 & Full & 866,941 & 17.48 & & $10,236,659$ & 39.87 & 57,876 & 48.99 \\
2016 & Restricted & 252,569 & 38.86 & & $6,263,151$ & 39.52 & 60,407 & 39.87 \\
\hline
\end{tabular}

Notes: The first part of the table contains firm-level summary statistics: "Observations" refers to the number of firms in each sample; "Employment" refers to the average firm size (i.e., number of employees per firm). The second half of the table contains employee-level summary statistics: "Observations" refers to the number of employees in each sample; "Age" and "Annual earnings" are cross-sectional averages in each sample; "\% Women" corresponds to the percentage of women in each sample.

with the size of the employing firm at time $t$ as well as the employment growth rate of the time $t$ employing firm between years $t$ and $t+1$. Firm size is defined as annual employment. We measure annual employment using payroll records (PD7), which contain monthly data on the number of employees. We average monthly employment over the course of the year to obtain annual employment. Employment growth is defined as the change in $(\log )$ annual employment between time $t$ and $t+1$.

We also disaggregate the analysis by mobility status. In particular, we sort workers into three groups: stayers (i.e., those who remain at the same main employer between time $t$ and $t+1$ ), non-laid-off movers (i.e., those who change their main employer between time $t$ and $t+1$ without experiencing a layoff), and laid-off movers (i.e., those who change their main employer between time $t$ and $t+1$ and experience a layoff). We define a layoff as a permanent separation from a worker's main employer due to a shortage of work. ${ }^{37}$ To determine whether a worker was laid off, we use ROEs filed by the employer. If, in year $t$ or $t+1$, a worker is laid off from his or her (year- $t$ ) main employer, then we assign this worker to the group of laid-off movers.

Finally, we explore the link between earnings dynamics and labor productivity growth, defining labor productivity as nominal value-added per worker (i.e., revenue minus non-labor expenses divided by employment). We residualize our measure of labor productivity by regressing its logarithm on year and industry fixed effects. Labor productivity growth is the change in residual (log) labor productivity between time $t$ and $t+1$.

\subsection{Empirical facts}

We now present four facts regarding the relationship between firm size (which we define as number of employees), firm growth (which we define as employment growth), and the earnings dynamics of workers.

\footnotetext{
${ }^{37}$ Permanent separation means that the worker does not return during the same year or next year. "Shortage of work" includes, for example, end of contracts/season/school year, shutdown of operations, position eliminated, company restructuring, and bankruptcy.
} 
Fact \#1: Average earnings growth is decreasing in firm size. It is well known that large firms tend to pay higher wages. ${ }^{38}$ We now show that there are substantial differences in the average earnings growth of workers across firm size groups. Figure 21(a) shows that average earnings growth among employees is weakly decreasing in firm size. The average earnings growth of workers at the smallest firms (i.e., less than 10 employees) is roughly $2 \log$ points higher than for workers at the largest firms (i.e., with 1000 or more employees).

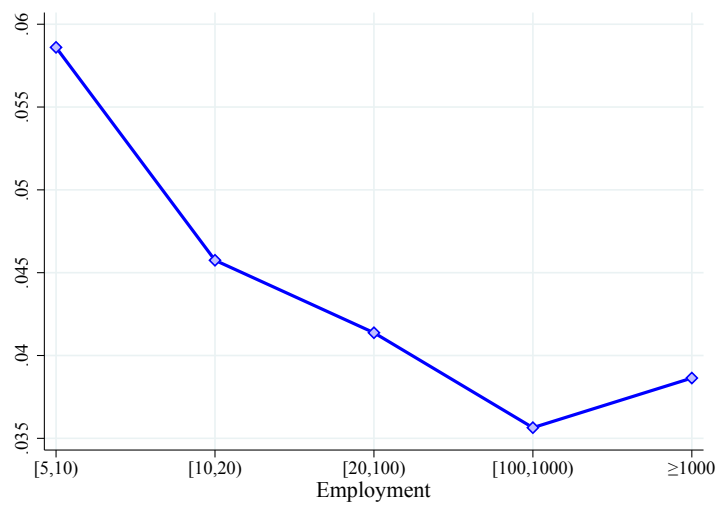

(a) Earnings growth (all)

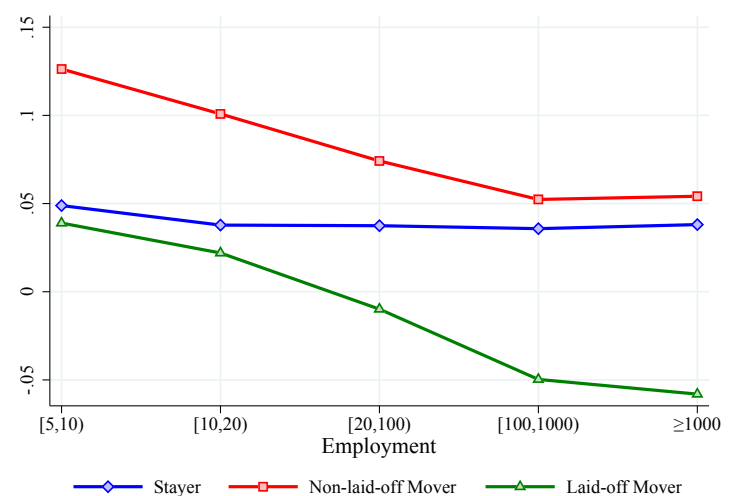

(b) Earnings growth (by mobility status)

Figure 21: Average residual earnings growth by firm size groups

We next show that the relationship between earnings growth and firm size is entirely driven by movers rather than stayers. Figure 21(b) contains average earnings growth by initial firm size group separately for stayers, non-laid-off movers, and laid-off movers. The average earnings growth of non-laid-off movers at the smallest firms is roughly $7 \mathrm{log}$ points higher than for non-laid-off movers at the largest firms. For movers who experience a layoff, the magnitude of the relationship is even stronger, with an average residual earnings growth differential of roughly $10 \log$ points between the smallest and largest firm size groups. In contrast, average earnings growth is unrelated to firm size for stayers.

Table 7: Transition probability by firm size groups

\begin{tabular}{llllll}
\hline & \multicolumn{5}{c}{ Firm size (number of employees) } \\
\cline { 2 - 6 } Mobility status & {$[5,10)$} & {$[10,20)$} & {$[20,100)$} & {$[100,1000)$} & $\geq 1000$ \\
\hline Stayers & 0.84 & 0.83 & 0.82 & 0.81 & 0.85 \\
Movers (no layoff) & 0.12 & 0.13 & 0.15 & 0.16 & 0.13 \\
Movers (layoff) & 0.039 & 0.038 & 0.036 & 0.030 & 0.016
\end{tabular}

Notes: Each entry reflects the proportion of each mobility status by firm size.

It is worth noting that the relationship between firm size and the earnings growth of movers is broadly

${ }^{38}$ See Morissette (1993) for evidence from Canada and Berlingieri, Calligaris, and Criscuolo (2018) for recent cross-country evidence. In Appendix Figure B1, we document a positive relationship between residual earnings and firm size in our sample. 
consistent with a "job-ladder" view of the labor market (e.g., Burdett and Mortensen, 1998). In job ladder models, workers "climb up" the job ladder by moving from small, low-wage firms toward large, high-wage firms. Workers moving out of small firms thus experience, on average, higher wage growth than those who move out of large firms. Workers who are laid off "fall down" the job ladder, which implies that they experience larger earnings declines than stayers and voluntary movers. In Appendix B, we show that it is indeed the case that workers at small firms tend to move to larger firms and vice versa (see Figure B3). Our results also corroborate findings in the existing literature that displaced workers experience large and persistent declines in labor earnings (e.g., Davis and von Wachter, 2011).

For completeness, Table 7 reports the fraction of stayers, non-laid-off movers, and laid-off movers by firm size. The two most notable features are that (i) the vast majority of workers remain at the same employer from one year to the next (roughly 85\%) and (ii) the fraction of laid-off movers is strongly decreasing in firm size, falling from $3.9 \%$ at firms with less than 10 employees to $1.6 \%$ at firms with more than 1000 employees.

Fact \#2: Earnings growth dispersion is decreasing in firm size. We now move on to studying the relationship between firm size and the volatility of earnings growth, focusing on log residual earnings growth dispersion as measured by the $90-10$ percentile difference. Figure 22(a) shows that earnings growth dispersion is strongly decreasing in firm size. To put this into perspective, the roughly 25 log point difference between earnings growth dispersion of workers at the largest and smallest firms is much greater than the fluctuations in earnings dispersion over the business cycle as documented in Figure 10. In Appendix Figure B2, we show that left and right tail dispersion (i.e., the 50-10 and 90-50 percentile differences) decline roughly equally with firm size.

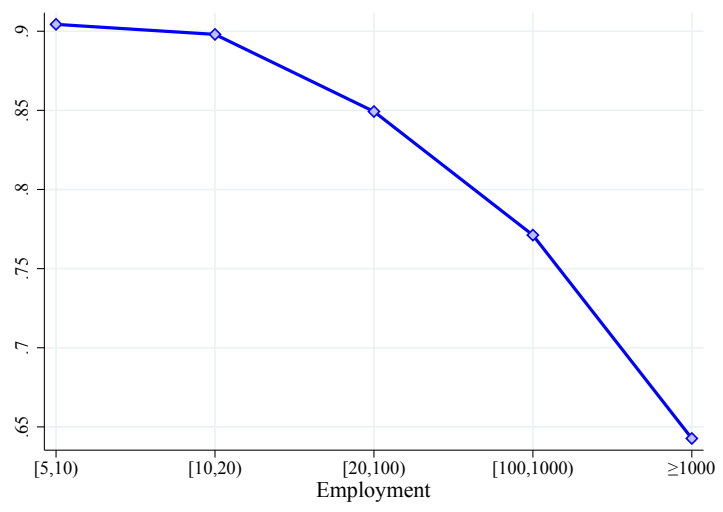

(a) Earnings growth dispersion (all)

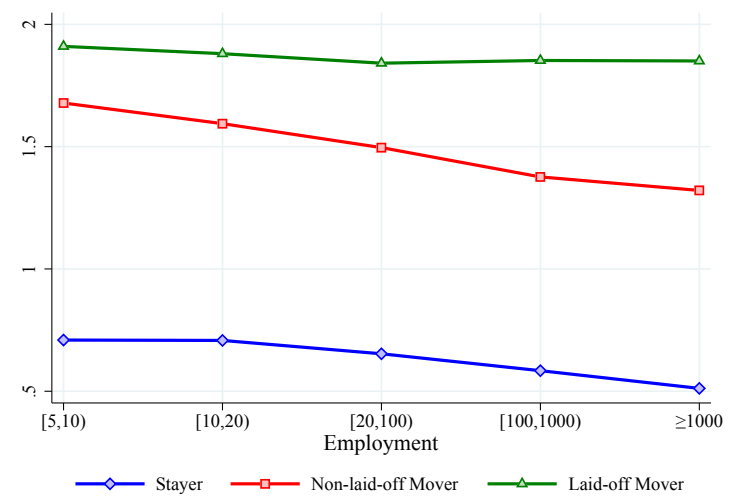

(b) Earnings growth dispersion (by mobility status)

Figure 22: Residual earnings growth dispersion by firm size groups

Notes: Earnings growth dispersion is defined as the 90-10 difference in residual log earnings growth.

Figure 22(b) disaggregates the results by mobility status. Two patterns stand out. First, the earnings dispersion of movers (both laid-off and non-laid-off) is much higher than for stayers, irrespective of the 
size of the employer. Focusing on workers at the largest firms (i.e., at least 1000 employees), the earnings dispersion of movers is 1.85 for those who experience a layoff and 0.91 for those who do not. In comparison, it is only 0.51 for stayers. Second, earnings dispersion is decreasing with firm size for both stayers and non-laid-off movers, with a "slope" that is comparable to that of the pooled sample. Comparing workers at the largest firms to those at the smallest, we see that earnings growth dispersion declines by roughly $20 \log$ points for stayers and $30 \log$ points for non-laid off movers (similar to the $25 \log$ point decline in the pooled sample).

Unlike the weak relationship between average earnings growth and firm size, dispersion in earnings growth is strongly decreasing in firm size for stayers (who account for the vast majority of workers). The reverse is true for laid-off workers. Altogether, these findings suggest that firm heterogeneity is not only an important determinant of average earnings growth, but it also affects the dispersion of earnings growth across workers.

Fact \#3: Average earnings growth increases with firm employment growth. While the aggregate growth rate of employment exhibits some variability over the business cycle, the distribution of employment growth rates across firms is extremely dispersed (see Bottazzi and Secchi, 2006 for empirical evidence). We now estimate whether employment growth rates are related to the average earnings growth of workers. To do so, we first sort firm-year observations by their employment growth rates and then construct 10 employment growth deciles within year and firm size group.

Figure 23(a) contains the average earnings growth of workers by firm growth deciles. A clear pattern emerges where earnings growth is strongly increasing in firm growth. For example, workers employed at firms in the top firm growth decile experience earnings growth that is roughly $15 \log$ points higher than workers at firms in the bottom firm growth decile. It is worth stressing that these magnitudes are extremely large. As a point of comparison, the average earnings growth differential by firm size groups was at most 2 $\log$ points. A more puzzling finding is the positive relationship between firm growth and earnings growth for movers (see Figure 23(b)).

One might hypothesize that high-skilled workers and top managers are rewarded more than the average workers for the growth of the firm, but our results point in the other direction. Figure 23(c) disaggregates the earnings growth of stayers by their (residualized) permanent earning levels (i.e., the variable defined as $\varepsilon_{t}^{P}$ earlier), sorting workers within each firm into five quintiles based on their permanent earnings. The figure shows that the relationship between earnings growth and firm growth is systematically stronger for workers at the lower end of the earnings distribution within firms. For those with the lowest permanent earnings (first quintile), the earnings growth differential between the top and bottom decile of firm growth is roughly 20 $\log$ points, compared to only $10 \log$ points for workers with the highest permanent earnings (fifth quintile). Figure 23(d) shows that the same pattern holds when looking at the very top of the permanent earnings 


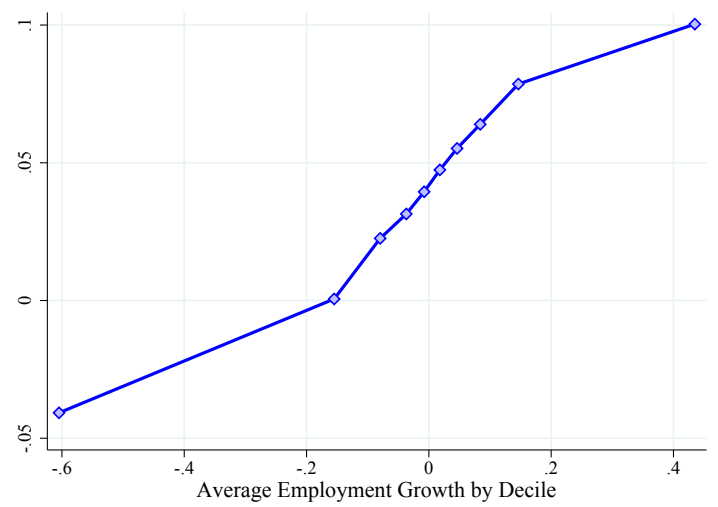

(a) All

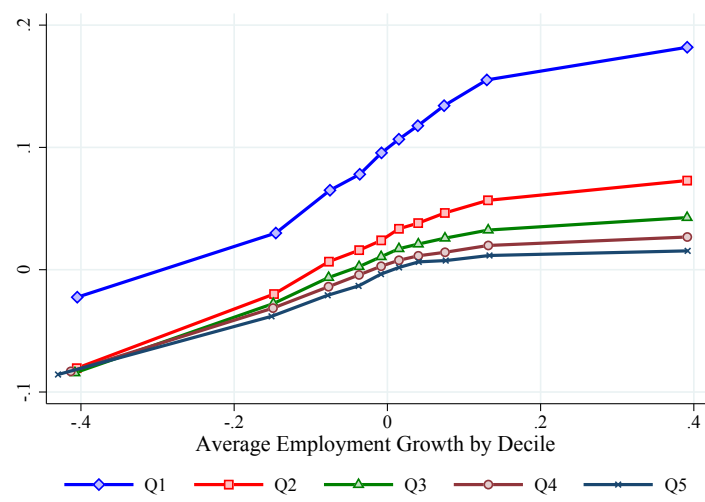

(c) By permanent earnings quintile (stayers only)

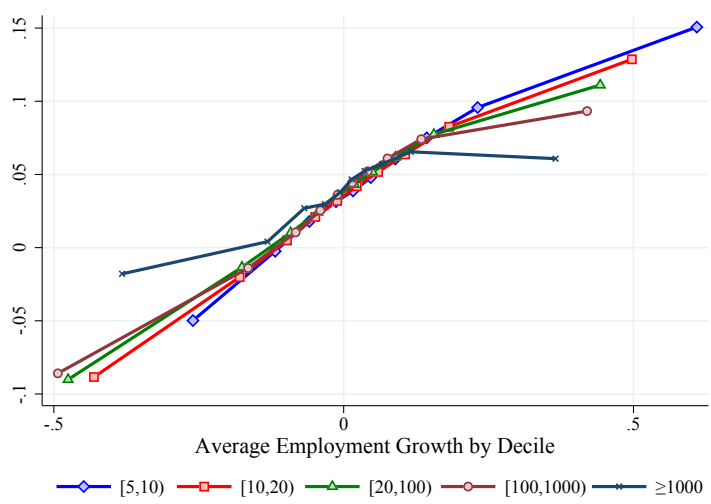

(e) By initial firm size group (stayers only)

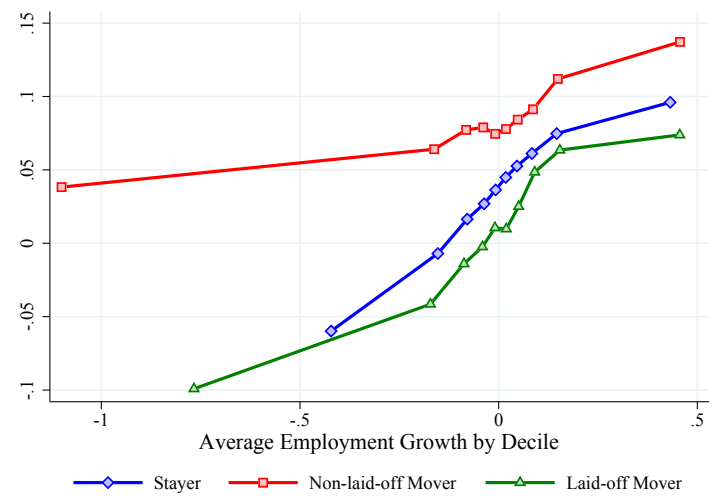

(b) By mobility status

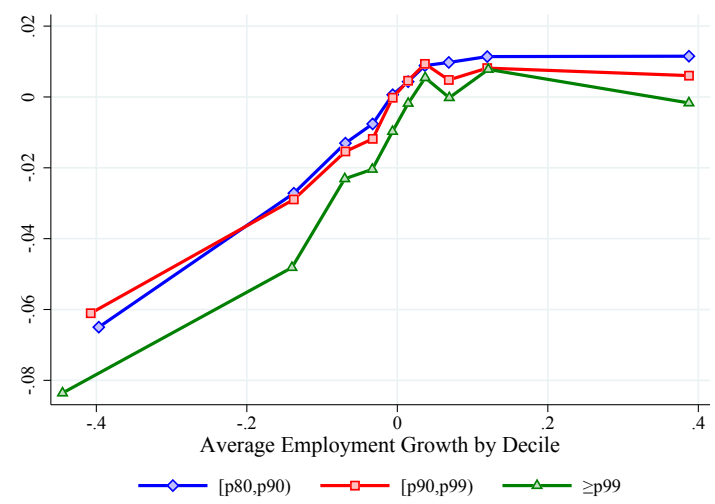

(d) By permanent earnings top percentiles (stayers only)

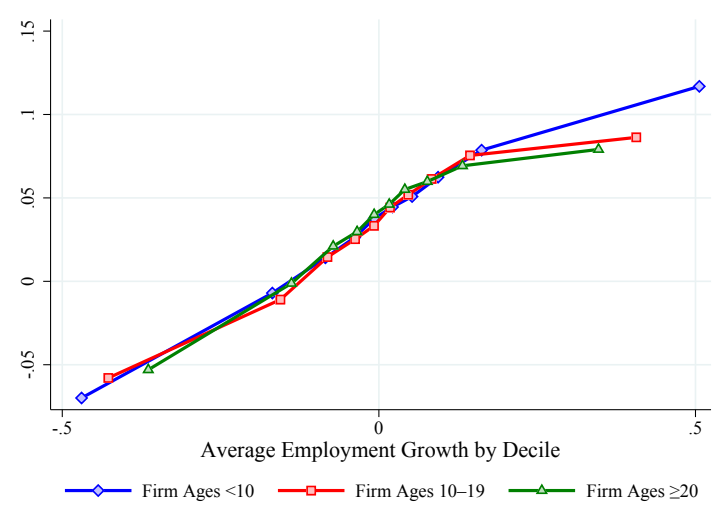

(f) By employer age group (stayers only)

Figure 23: Average earnings growth by employment growth groups

Notes: Panel (c) restricts the sample to firms with at least 10 observed workers, while panel (d) restricts the sample to firms with at least 100 observed workers.

distribution within firms. ${ }^{39}$ Finally, Figures 23(e) and 23(f) break down the relationship between earnings

${ }^{39}$ When conditioning on workers in different permanent earnings quintiles (Figure 23(c)), we consider workers from firms with at least 10 observed employees. When conditioning on top permanent earnings percentiles (Figure 23(d)), we consider workers from firms with at least 100 observed employees. 


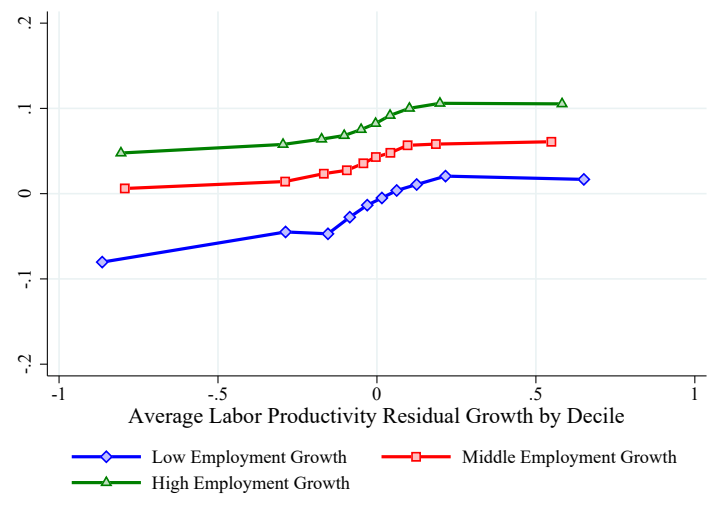

(a) By labor productivity growth deciles (stayers only)

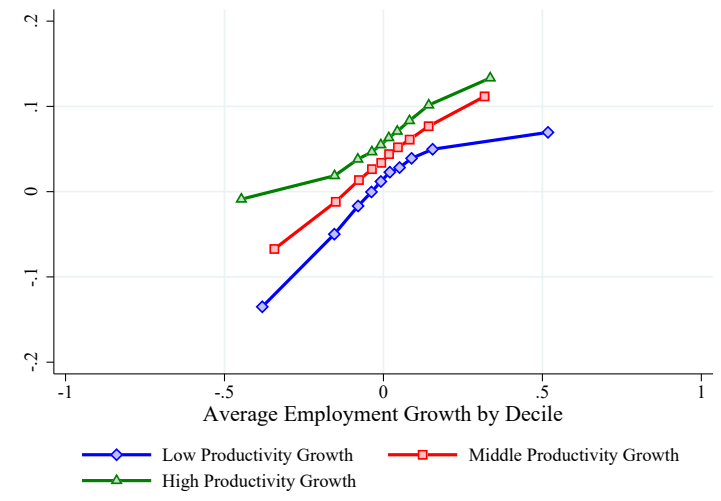

(b) By employment growth deciles (stayers only)

Figure 24: Average earnings growth by labor productivity growth and employment growth groups

growth (for stayers) and firm growth by initial firm size and firm age, respectively. Our main finding is robust, with a slightly stronger relationship for small firms.

The relationship that we uncover between earnings growth and firm employment growth is reminiscent of the finding that there is a positive (yet incomplete) pass-through of firm productivity to wages (e.g., Guiso, Pistaferri, and Schivardi, 2005). If employment growth were fully determined by productivity growth, then our results would merely be a restatement of the existence of a wage-productivity pass-through. In practice, there is considerable heterogeneity in productivity growth rates conditional on employment growth, which allows us to examine the relative effect of productivity growth versus employment growth on earnings.

For simplicity, we construct three employment growth groups: "low employment growth" reflects firms in the bottom 3 deciles of employment growth, "middle employment growth" reflects the middle 4 deciles, and "high employment growth" reflects the top 3 deciles. As we can see in Figure 23(a), the "middle employment growth" group contains firms with stable employment (growth generally less than 10\% annually in absolute value), while the two other groups contain firms with very rapid employment growth or sizeable employment losses. Within each of these groups, we sort firms into 10 deciles of labor productivity growth.

Figure 24(a) plots the average earnings growth of workers (stayers only) by labor productivity growth decile for each of the three employment growth groups. Two patterns stand out. First, average earnings growth is increasing in labor productivity growth. For example, in the "middle employment growth" group, workers at firms in the top decile of labor productivity growth experience average earnings growth of roughly $5.5 \log$ points higher than those at firms in the bottom decile. This is consistent with an imperfect pass-through of productivity to wages, as the previous literature has documented. ${ }^{40}$ Second, the effect of employment growth on average earnings growth is large, even conditional on labor productivity growth. For instance, among workers in the bottom decile of labor productivity growth, workers in "high employment

${ }^{40}$ Note, however, that our measure of firm productivity (i.e., value added per worker in revenue terms) is different from other productivity measures sometimes used, such as total factor productivity. For instance, a change in (revenue) labor productivity can be due to an increase in the capital stock per worker or a change in the price markup. 
growth" firms experience average earnings growth that is about $13 \log$ points higher than workers in "low employment growth" firms.

The importance of firm employment growth is even more clear in Figure 24(b). Here, we construct three labor productivity growth groups, defining "low productivity growth" as firms in the bottom 3 deciles of productivity growth, "middle productivity growth" as firms in the middle 4 deciles, and "high productivity growth" as firms in the top 3 deciles. Figure 24(b) plots the average earnings growth of workers (stayers only) by employment growth decile for each of the three labor productivity growth groups. Again, we see that average earnings growth is increasing for workers in firms with high employment growth (i.e., fact \#3) even when controlling for labor productivity growth. Moreover, the gradient between earnings growth and employment growth is much steeper than that between earnings growth and labor productivity growth.

So far, our analysis has focused on workers for whom we can observe both firm growth and earnings growth. As a result, we have excluded workers whose employer exits between time $t$ and $t+1$. In Appendix $\mathrm{B}$ we repeat the analysis by including those observations. We obtain results that are coherent with what we have found thus far. In particular, Figure B4(b) shows that movers out of exiting firms experience an average earnings growth comparable to that of movers out of rapidly shrinking firms (i.e., first decile of employment growth).

Overall, our analysis indicates that the earnings trajectory of workers is tightly linked to the employment growth of their employing firms. Workers who join high-growth firms experience above-average earnings growth, while those who join rapidly shrinking firms experience below-average earnings growth. Furthermore, the relationship between employment growth appears to be even stronger than that for labor productivity growth. One caveat is that our measure of labor productivity growth may be "noisier" than our measure of employment growth, which would lead to a greater measurement error attenuation bias for the productivity growth - earnings growth relationship.

Fact \#4: Earnings growth dispersion is a U-shaped function of firm employment growth. We now turn to the relationship between earnings growth dispersion and firm employment growth. Figure 25(a) shows that earnings growth dispersion (i.e., 90-10 difference for residual log earnings growth) is a U-shaped function of firm employment growth. Workers at rapidly shrinking and at fast-growing firms face considerable dispersion in their earnings growth, while workers at firms with stable employment experience much less dispersion in their earnings growth. Inspecting the relationship by mobility group, we find that the U-shaped relationship is entirely driven by stayers (see Figure 25(b)). In contrast, the earnings growth dispersion of movers appears to be increasing in firm employment growth.

We next decompose the earnings growth dispersion for stayers into left-tail dispersion (i.e., the 5010 difference) and right-tail dispersion (i.e., the 90-50 difference). This reveals opposing "hockey stick" patterns, where workers at low-growth firms face a high level of left-tail dispersion while workers at highgrowth firms face a high level of right-tail dispersion (see Figure 25(c)). This finding is consistent with 


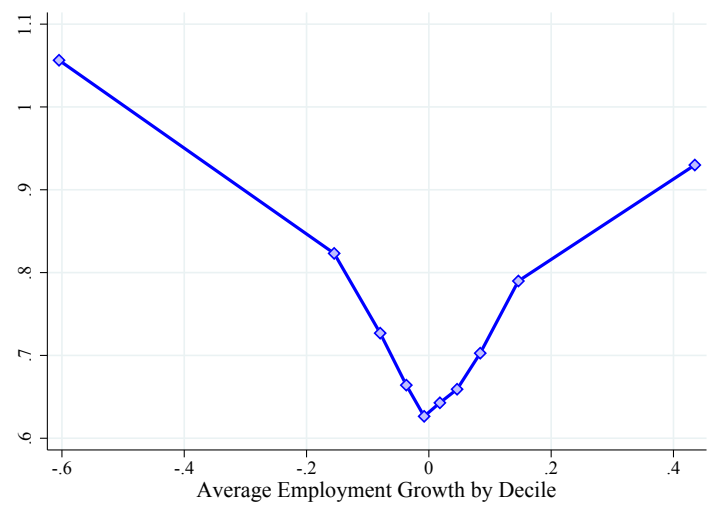

(a) Earnings growth dispersion (all)

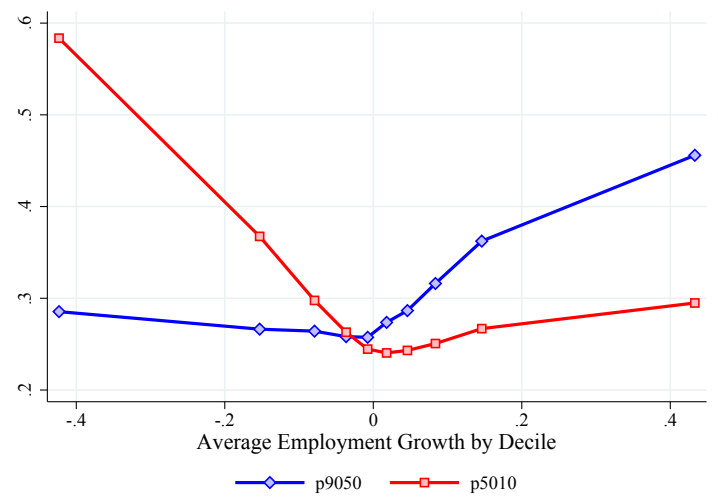

(c) Earnings growth dispersion in both tails (stayers only)

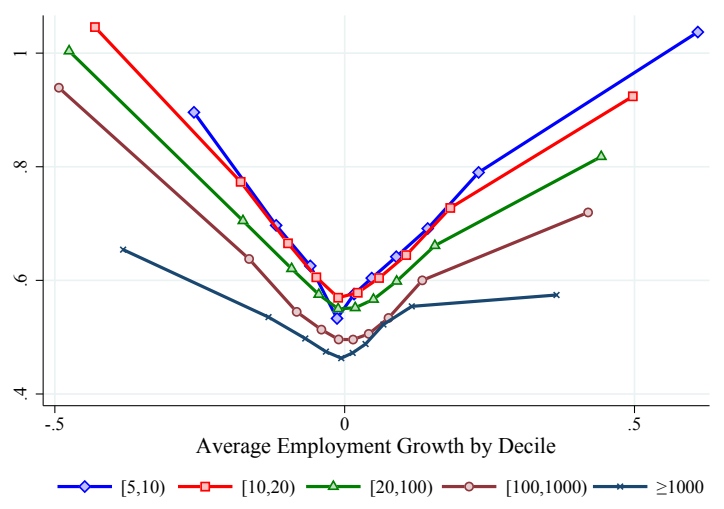

(e) By firm size groups (stayers only)

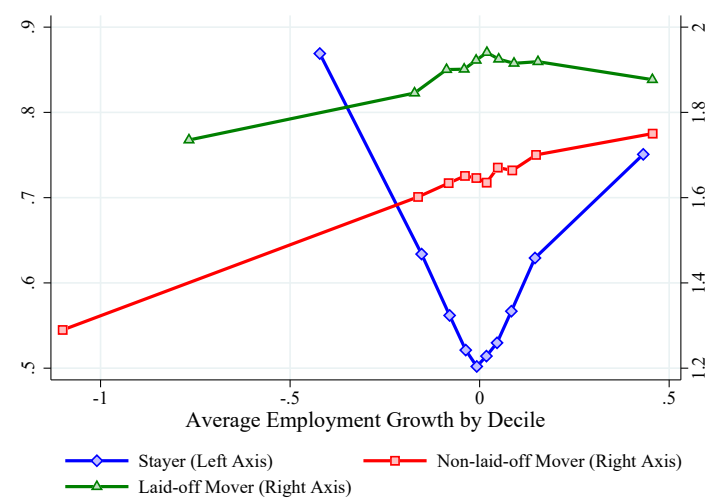

(b) Earnings growth dispersion by mobility status

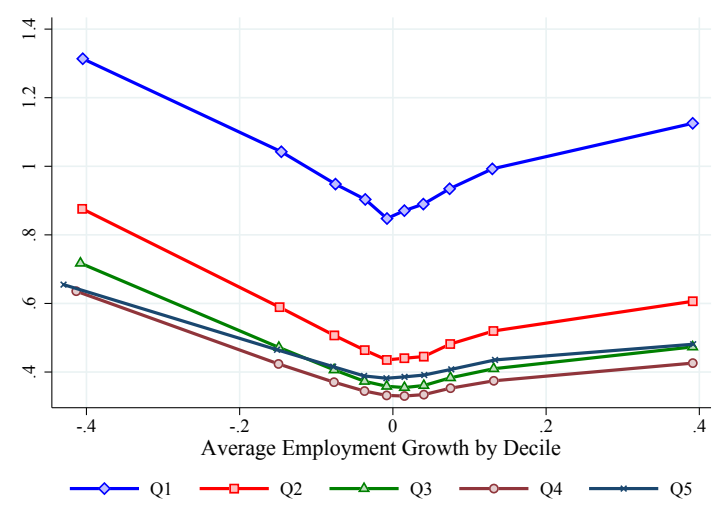

(d) By permanent earnings quintile (stayers only)

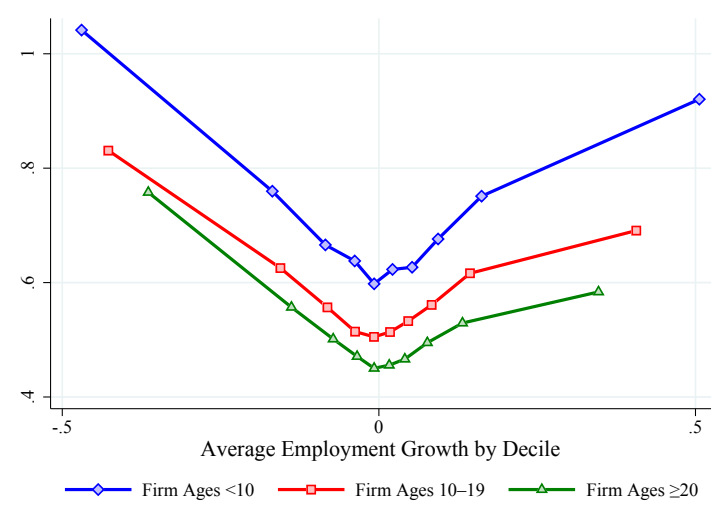

(f) By firm age groups (stayers only)

Figure 25: Residual earnings growth dispersion by employment growth groups

Notes: Earnings growth dispersion is defined as the $90-10$ difference in residual log earnings growth.

the idea that downside risk increases when firms contract, while upside risk increases when firms expand employment. These patterns are consistent with the macro relationship between aggregate employment and earnings dispersion first documented in Guvenen, Ozkan, and Song (2014). In particular, expansions are characterized by an increase in right-tail dispersion (upside risk), while recessions are characterized by an 
increase in left-tail dispersion (downside risk).

Next, we disaggregate the analysis (for stayers) by sorting workers into permanent earnings quintiles. We see that the U-shaped relationship holds within each quintile (see Figure 25(d)), where the two lowest earnings quintiles (especially the lowest) experience a much higher level of earnings growth dispersion than the other three quintiles. Finally, in Figures 25(e) and 25(f), we repeat the analysis by sorting workers into firm size and firm age groups. Our main result is robust: the earnings growth dispersion of stayers is a U-shaped function of firm growth (with dispersion especially high for stayers at sharply contracting firms). As we did for fact \#3, we repeat the analysis by including exiting firms and obtain coherent results (see Figure B5 in Appendix B).

Altogether, our findings demonstrate that workers who join fast-growing firms can expect not only faster earnings growth on average, but their earnings growth distribution will be more positively skewed with very limited downside risk. By contrast, workers at rapidly shrinking firms experience low average earnings growth with little upside risk and a negatively skewed distribution. Finally, workers joining firms with stable employment typically experience moderate earnings growth and little dispersion.

\section{Conclusions}

This paper provides a comprehensive examination of earnings inequality, volatility, and mobility in Canada from 1983 to 2016. Further, starting in 2001, we use Canadian matched employer-employee data to explore the joint dynamics of workers and firms. Our most novel contribution with these data is our analysis of the relationship between the earnings growth of workers and the employment growth of their employers.

Our first main finding sets Canada apart from many other countries (especially the U.S.): we find only modest changes in most measures of overall earnings inequality, volatility, and mobility between 1983 and 2016. For example, the 90-10 male earnings ratio grew far less in Canada than it did in the U.S., while the ratio actually declined slightly for Canadian women. Underlying this stability, we find that the 90-50 earnings ratio increased slowly but consistently over time; however, this was largely offset by reductions in the 50-10 ratio. This apparent stability hides a few notable trends, however, including a nearly $30 \%$ increase in earnings of women relative to men (at the median) and a meteoric rise in earnings among those at the very top of the earnings distribution. Meanwhile, earnings volatility (as measured by 90-10, 90-50, or 50-10 ratios for annual earnings growth) declined only slightly over the lengthy period we study, while transition matrices of 5- and 10-year mobility showed reduced persistence in the middle of the distribution (with slightly more downward mobility) coupled with sustained persistence in the tails.

Second, despite the relative stability of earnings inequality and volatility over the long term, we document substantial movements over the business cycle. Sharp (temporary) increases in earnings inequality and volatility, driven mainly by significant earnings losses for younger workers and men at the bottom of the earnings distribution, occurred during both the early 1990s recession and the Great Recession. Those at 
the very top of the earnings distribution (i.e., top 1\%) also experienced heavy losses during these economic downturns. These strong cyclical patterns are similar to those documented in the U.S. (e.g., Bloom et al., 2017; Guvenen et al., 2018).

It is natural to ask how Canada avoided the substantial increases inequality (except at the very top) experienced in the U.S. and many other developed countries. Noting sizeable increases in the returns to schooling, many studies point to (skill-biased) technological change as an important factor in rising inequality around the world. Although the Canadian tax files do not contain information about education, previous studies have shown that returns to schooling increased much less in Canada than in the U.S. (e.g., Boudarbat, Lemieux, and Riddell, 2010; Bowlus, Liu, and Robinson, 2019). Observing better labor market performance among less-educated older workers in Canada relative to the U.S., Bowlus, Liu, and Robinson (2019) conjecture that this may be the result of higher Canadian unionization rates and growth in public sector employment protecting these workers from wage reductions. Card, Lemieux, and Riddell (2004) further suggest that weaker union declines in Canada (relative to the U.S. and U.K.) may partially explain its more modest increases in inequality over the 1980s and 1990s. Finally, we note that the earnings of less-skilled workers in Canada have been bolstered by more regular increases in provincial minimum wages, a sizable resource sector, and strengthened work incentives in social assistance programs that are not limited to single mothers (as in the U.S.).

Over this same period, Canada has experienced a more modest increase in earnings over the upper part of the distribution (except at the very top) compared to the U.S. Two supply-based changes have been identified here. First, Fortin et al. (2012) argue that the returns to higher education rose less in Canada due to faster growth in post-secondary enrolment. Second, Aydemir and Borjas (2007) estimate that Canada's focus on admitting high-skilled immigrants dampened its university earnings premium, while greater numbers of low-skilled immigrants led to an increase in the U.S. premium. Yet, these forces did little to hold back the top $1 \%$ in Canada, who experienced dramatic increases in earnings comparable to those observed in the U.S. The reasons for this are not yet understood, but Saez and Veall (2005) speculate that it may be due to the tightly integrated labor market for highly skilled workers.

Our second finding highlights the devastating losses experienced by many Canadian workers (especially younger workers) during major economic downturns. Based on aggregate employment and output, as well as earnings inequality and volatility, the early 1990s recession had much larger effects than other recessions, including the Great Recession, which was much deeper and longer lasting in the U.S. Although the American and Canadian economies are tied through trade, tourism, and labor flows, it is clear that important differences in sectoral composition and economic policies have resulted in heterogeneous responses to shared economic disruptions. Much work is still needed to better understand these differences.

Our analysis of firm and worker dynamics reveals a third important finding. Workers at fast-growing firms experience faster earnings growth and less downside risk than workers at rapidly shrinking firms, who experience low (or negative) average earnings growth and little upside risk. Further, workers at firms with 
stable employment typically experience moderate earnings growth with little upside or downside risk. The strong positive relationship between earnings growth and firm employment growth exists across firms of different sizes and ages, as well as across workers with different levels of recent earnings. The latter suggests that workers across the firm skill distribution (or firm hierarchy) share in the benefits of expansion.

Our findings on worker earnings and firm employment dynamics deepen our understanding of the sources of individual earnings growth and idiosyncratic earnings risk. Employers play an important role in shaping the earnings trajectories of their workers, not just their earnings levels. But, the extent to which idiosyncratic earnings risk is explained by the risks faced by firms remains an open question. Layoffs are an important source of downside risk, while changing employers voluntarily presents an opportunity for upward mobility. Considerable cross-sectional variation in individual earnings risk across the firm growth distribution suggests that cyclical fluctuations in the firm growth distribution could be an important source of variation in individual earnings risk over the business cycle.

Of course, the empirical relationship between earnings dynamics and firm dynamics need not reflect a causal relationship. Even so, our findings can help in identifying and disciplining economic mechanisms important for the joint dynamics of firms and their workers. For example, the fact that firm growth is still correlated with earnings growth even after workers leave the firm may indicate that high-growth firms tend to hire high-growth workers. The fact that earnings growth is more strongly correlated with firm employment growth than productivity growth may suggest that firms must pay more when they want to expand their workforce; however, they may choose not to adjust employment immediately in response to productivity shocks. We leave a more in-depth treatment of these issues for future research.

\section{References}

Acemoglu, Daron and David Autor. 2011. "Skills, tasks and technologies: Implications for employment and earnings.” In Handbook of Labor Economics, vol. 4B. Elsevier, 1043-1171.

Aydemir, Abdurrahman and George J. Borjas. 2007. "Cross-Country Variation in the Impact of International Migration: Canada, Mexico, and the United States." Journal of the European Economic Association 5 (4):663-708.

Baker, Michael and Kevin Milligan. 2008. "How Does Job-Protected Maternity Leave Affect Mothers' Employment?" Journal of Labor Economics 26 (4):655-691.

Baker, Michael and Gary Solon. 2003. "Earnings dynamics and inequality among Canadian men, 1976-1992: Evidence from longitudinal income tax records." Journal of Labor Economics 21 (2):289-321.

Beach, Charles. 2016. "What has happened to middle-class earnings in Canada?" In Income inequality: The Canadian story, edited by David A. Green, W. Craig Riddell, and France St.-Hillaire. Institute for Research on Public Policy, 157-176.

Beach, Charles and Ross Finnie. 1998. "Earnings mobility 1982-1994: Women gaining ground and lower paid males slipping." Canadian Business Economics 6 (4):3-25. 
- 2004. "A longitudinal analysis of earnings change in Canada." Canadian Journal of Economics 37 (1):219-240.

Beaudry, Paul and John DiNardo. 1991. "The effect of implicit contracts on the movement of wages over the business cycle: Evidence from micro data.” Journal of Political Economy 99 (4):665-688.

Beaudry, Paul and David A. Green. 2000. "Cohort patterns in Canadian earnings: Assessing the role of skill premia in inequality trends." Canadian Journal of Economics 33 (4):907-936.

Berlingieri, Giuseppe, Sara Calligaris, and Chiara Criscuolo. 2018. "The productivity-wage premium: Does size still matter in a service economy?" AEA Papers and Proceedings 108:328-33.

Bilal, Adrien G., Niklas Engbom, Simon Mongey, and Giovanni L. Violante. 2019. "Firm and Worker Dynamics in a Frictional Labor Market." Working Paper 26547, National Bureau of Economic Research.

Bloom, Nicholas, Fatih Guvenen, Luigi Pistaferri, John Sabelhaus, Sergio Salgado, and Jae Song. 2017. "The Great Micro Moderation.” Working Paper.

Bottazzi, Giulio and Angelo Secchi. 2006. "Explaining the distribution of firm growth rates." The RAND Journal of Economics 37 (2):235-256.

Boudarbat, Brahim, Thomas Lemieux, and W. Craig Riddell. 2010. "The evolution of the returns to human capital in Canada, 1980-2005." Canadian Public Policy 36 (1):63-89.

Bowlus, Audra J., Haoming Liu, and Chris Robinson. 2019. "Different Paths? Human Capital Prices, Wages, and Inequality in Canada and the United States." Journal of Labor Economics 37 (S2):S689-S734.

Bowlus, Audra J. and Jean-Marc Robin. 2012. "An international comparison of lifetime inequality: How continental Europe resembles North America." Journal of the European Economic Association 10 (6):12361262.

Brzozowski, Matthew, Martin Gervais, Paul Klein, and Michio Suzuki. 2010. "Consumption, income, and wealth inequality in Canada." Review of Economic Dynamics 13 (1):52-75.

Buchinsky, Moshe and Jennifer Hunt. 1999. "Wage Mobility in the United States." Review of Economics and Statistics 81 (3):351-368.

Burdett, Kenneth and Dale T. Mortensen. 1998. "Wage differentials, employer size, and unemployment." International Economic Review 39 (2):257-273.

Card, David, Thomas Lemieux, and W. Craig Riddell. 2004. "Unions and wage inequality." Journal of Labor Research 25 (4):519-562.

- 2020. "Unions and wage inequality: The roles of gender, skill and public sector employment." Canadian Journal of Economics 53 (1):140-173.

Coles, Melvyn G. and Dale T. Mortensen. 2016. "Equilibrium Labor Turnover, Firm Growth, and Unemployment." Econometrica 84 (1):347-363.

Constantinides, George M. and Darrell Duffie. 1996. "Asset pricing with heterogeneous consumers.” Journal of Political Economy 104 (2):219-240. 
Davis, Steven J. and Till von Wachter. 2011. "Recessions and the costs of job loss." Brookings Papers on Economic Activity 42 (2):1-72.

Elsby, Michael W. L. and Axel Gottfries. 2019. "Firm Dynamics, On-The-Job Search and Labor Market Fluctuations." Working paper.

Finnie, Ross and Ian Irvine. 2011. "The Redistributional Impact of Canada's Employment Insurance Program, 1992-2002.” Canadian Public Policy 37 (2):201-218.

Forsythe, Eliza. 2019. “Why Don’t Firms Hire Young Workers During Recessions?” Working Paper.

Fortin, Nicole, David A. Green, Thomas Lemieux, Kevin Milligan, and W. Craig Riddell. 2012. "Canadian Inequality: Recent Developments and Policy Options.” Canadian Public Policy 38 (2):121-145.

Fortin, Nicole and Thomas Lemieux. 2015. "Changes in wage inequality in Canada: An interprovincial perspective." Canadian Journal of Economics 48 (2):682-713.

Fortin, Pierre. 1996. “The great Canadian slump.” Canadian Journal of Economics 29 (4):761-787.

Freedman, Charles and Tiff Macklem. 1998. “A Comment on 'The Great Canadian Slump'.” Canadian Journal of Economics 31 (3):646-665.

Frenette, Marc, David A. Green, and Kevin Milligan. 2009. "Taxes, transfers, and Canadian income inequality." Canadian Public Policy 35 (4):389-411.

Frenette, Marc, David A. Green, and Garnett Picot. 2006. "Rising Income Inequality in the 1990s: An Exploration of Three Data Sources." In Dimensions of Inequality in Canada, edited by David A. Green and Jonathan R. Kesselman. Vancouver: University of British Columbia Press, 173-204.

Gee, Kar-Fai, Huju Liu, and Carlos Rosell. 2020. "Understanding Developments in Individuals' Earnings Dispersion in Canada Using Matched Employer-Employee Data." Catalogue no. 11F0019M 444, Statistics Canada.

Gottschalk, Peter and Robert Moffitt. 1994. "The Growth of Earnings Instability in the U.S. Labor Market." Brookings Papers on Economic Activity 25 (2):217-272.

Gouin-Bonenfant, Emilien. 2018. "Productivity Dispersion, Between-firm Competition and the Labor Share." Meeting Papers 1171, Society for Economic Dynamics.

Green, David A. and Benjamin M. Sand. 2015. "Has the Canadian labour market polarized?" Canadian Journal of Economics 48 (2):612-646.

Guiso, Luigi, Luigi Pistaferri, and Fabiano Schivardi. 2005. "Insurance within the firm." Journal of Political Economy 113 (5):1054-1087.

Guvenen, Fatih, Greg Kaplan, and Jae Song. 2014. "How risky are recessions for top earners?" American Economic Review 104 (5):148-53.

Guvenen, Fatih, Greg Kaplan, Jae Song, and Justin Weidner. 2018. "Lifetime Incomes in the United States over Six Decades." Working Paper.

Guvenen, Fatih, Fatih Karahan, Serdar Ozkan, and Jae Song. 2019. "What Do Data on Millions of U.S. Workers Reveal about Life-Cycle Earnings Dynamics?” Working Paper. 
Guvenen, Fatih, Serdar Ozkan, and Jae Song. 2014. "The nature of countercyclical income risk." Journal of Political Economy 122 (3):621-660.

Heathcote, Jonathan, Fabrizio Perri, and Giovanni L. Violante. 2010. "Unequal we stand: An empirical analysis of economic inequality in the United States, 1967-2006." Review of Economic Dynamics $13(1): 15-51$.

Hershbein, Brad and Lisa B. Kahn. 2018. "Do recessions accelerate routine-biased technological change? Evidence from vacancy postings.” American Economic Review 108 (7):1737-1772.

Hoynes, Hilary, Douglas L. Miller, and Jessamyn Schaller. 2012. "Who Suffers During Recessions?” Journal of Economic Perspectives 26 (3):27-48.

Hubmer, Joachim. 2018. "The job ladder and its implications for earnings risk." Review of Economic Dynamics 29:172-194.

Jacobson, Louis S., Robert J. LaLonde, and Daniel G. Sullivan. 1993. "Earnings losses of displaced workers." American Economic Review 83 (4):685-709.

Kaas, Leo and Philipp Kircher. 2015. "Efficient firm dynamics in a frictional labor market." American Economic Review 105 (10):3030-3060.

Kocherlakota, Narayana and Luigi Pistaferri. 2009. "Asset pricing implications of Pareto optimality with private information." Journal of Political Economy 117 (3):555-590.

Lammam, Charles, Amela Karabegović, and Neils Veldhuis. 2012. "Measuring income mobility in Canada." Tech. rep., Studies in Economic Prosperity. Fraser Institute.

Mankiw, Gregory. 1986. "The equity premium and the concentration of aggregate shocks." Journal of Financial Economics 17 (1):211-219.

Messacar, Derek. 2017. "Big tax data and economic analysis: Effects of personal income tax reassessments and delayed tax filing." Canadian Public Policy 43 (3):261-283.

Milligan, Kevin. 2016. "The Tax Recognition of Children in Canada: Exemptions, Credits and Cash Transfers." Canadian Tax Journal 64 (3):601-618.

Milligan, Kevin and Michael Smart. 2015. "Taxation and top incomes in Canada." Canadian Journal of Economics 48 (2):655-681.

Milligan, Kevin and Mark Stabile. 2007. "The integration of child tax credits and welfare: Evidence from the Canadian National Child Benefit program.” Journal of Public Economics 91 (1-2):305-326.

Moffitt, Robert. 2020. "Reconciling Trends in U.S. Male Earnings Volatility: Results from a Four Data Set Project.” Working Paper 27664, National Bureau of Economic Research.

Moffitt, Robert and Peter Gottschalk. 2012. "Trends in the transitory variance of male earnings: Methods and evidence." Journal of Human Resources 47 (1):204-236.

Morissette, Rene. 1993. "Canadian jobs and firm size: Do smaller firms pay less?" Canadian Journal of Economics 26 (1):159-174. 
Morissette, Rene and Charles Berube. 1996. "Longitudinal Aspects of Earnings Inequality in Canada." Working Paper 94, Statistics Canada.

Picot, Garnett. 2001. "Working Time, Wages, and Earnings Inequality among Men and Women in Canada, 1981-1993." In Working Time in Comparative Perspective, vol. 1, edited by Ging Wong and Garnett Picot. Kalamazoo, MI: W.E. Upjohn Institute for Employment Research, 109-143.

Sabelhaus, John and Jae Song. 2010. "The Great Moderation in Micro Labor Earnings.” Journal of Monetary Economics 57 (4):391-403.

Saez, Emmanuel and Michael R. Veall. 2005. "The Evolution of High Incomes in Northern America: Lessons from Canadian Evidence.” American Economic Review 95 (3):831-849.

Trefler, Daniel. 2004. "The Long and Short of the Canada-U.S. Free Trade Agreement." American Economic Review 94 (4):870-895.

Veall, Michael R. 2012. "Top income shares in Canada: Recent trends and policy implications." Canadian Journal of Economics 45 (4):1247-1272. 